BNL -66576

Informal Report

\title{
DEVELOPMENT AND DEMONSTRATION OF POLYMER MICROENCAPSULATION OF MIXED WASTE USING KINETIC MIXER PROCESSING
}

TTP No. CH36MW63

FINAL REPORT

P.R. Lageraaen, P.D. Kalb, L.W. Milian, J.W. Adams

November 1997

Prepared by:

Environrnental \& Waste Technology Center

Department of Advanced Technology

Brookhaven National Laboratory

Prepared for:

Mixed Waste Focus Area

Office of Science and Technology

United States Department of Energy

Contract No. DE-AC02-98CH10886 


\begin{abstract}
Thermokinetic mixing was investigated as an alternative processing method for polyethylene microencapsulation, a technology well demonstrated for treatment of hazardous, low-level radioactive and low-level mixed wastes. Polyethylene encapsulation by extrusion has been previously shown to be applicable to a wide range of waste types but often pretreatment of the wastes is necessary due to process limitations regarding the maximum waste moisture content and particle size distribution. Development testing was conducted with kinetic mixing in order to demonstrate technology viability and show improved process applicability in these areas. Testing to establish process capabilities and relevant operating parameters was performed with waste surrogates including an aqueous evaporator concentrate and soil. Using a pilot-scale kinetic mixer which was installed and modified for this program, the maximum waste moisture content and particle size was determined. Following process development with surrogate wastes, the technology was successfully demonstrated at BNL using actual mixed waste.
\end{abstract}




\section{, \\ ,}




\section{TABLE OF CONTENTS}

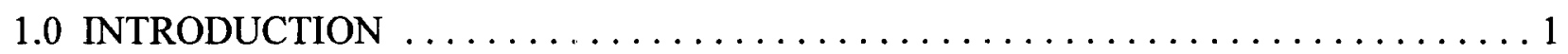

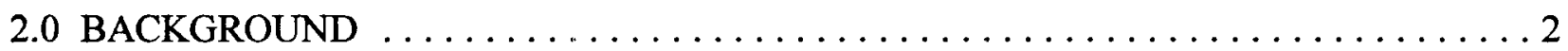

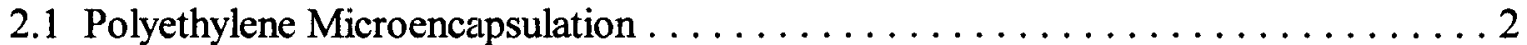

2.2 Kinetic Mixing Process and Equipment Description $\ldots \ldots \ldots \ldots \ldots \ldots \ldots$

2.3 Kinetic Mixer System Modifications and Improvements . . . . . . . . . . 5

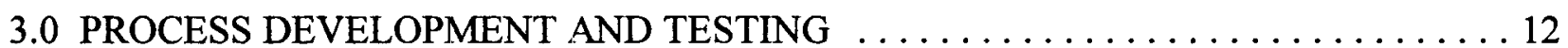

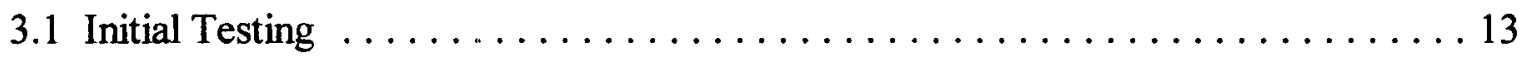

3.1.1 Effect of moisture content on batch cycle time $\ldots \ldots \ldots \ldots \ldots \ldots 14$

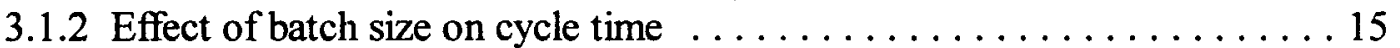

3.1.3 Comparison polyethylene melt indices ................. 16

3.1.4 Comparison of extrusion and kinetic mixing product density . . . . . 17

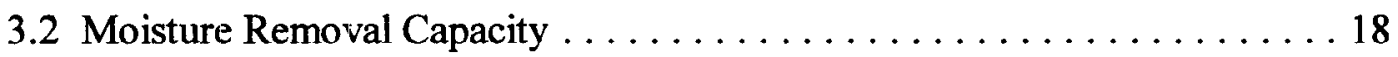

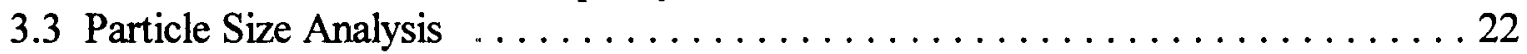

3.4 Recycled Plastic Processing . . . . . . . . . . . . . . . . . . . . . . 24

4.0 MIXED WASTE PROCESSING DEMONSTRATION $\ldots \ldots \ldots \ldots \ldots \ldots \ldots$

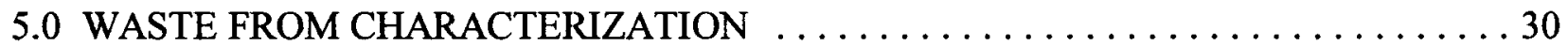

5.1 Recycled Plastic Waste Form Performance $\ldots \ldots \ldots \ldots \ldots \ldots \ldots \ldots \ldots \ldots \ldots$

5.2 Mixed Waste Encapsulated Product Performance ................. 33

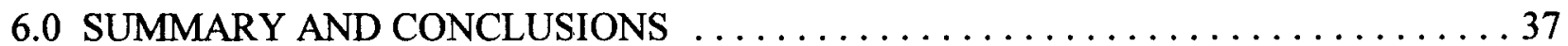

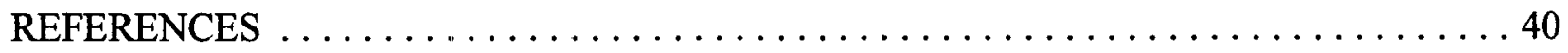




\section{LIST OF FIGURES}

Figure $2.1 \quad$ Sketch of the pilot-scale kinetic mixer $\ldots \ldots \ldots \ldots \ldots \ldots \ldots \ldots \ldots$

Figure $2.2 \quad$ Photograph of kinetic mixer after installation at $\mathrm{BNL} \ldots \ldots \ldots \ldots \ldots \ldots$

Figure $2.3 \quad$ Kinetic mixer installed at BNL with modified feed tube $\ldots \ldots \ldots \ldots \ldots$

Figure 2.4 Schematic of kinetic mixer off gas system $\ldots \ldots \ldots \ldots \ldots \ldots \ldots \ldots \ldots \ldots$

Figure 2.5 Photograph of kinetic mixer off gas system $\ldots \ldots \ldots \ldots \ldots \ldots \ldots \ldots \ldots$

Figure 2.6 Photograph of kinetic mixer with end flange removed for access to mixing blades

Figure 2.7 Photograph of mixing blade sleeve $\ldots \ldots \ldots \ldots \ldots \ldots \ldots \ldots \ldots \ldots \ldots$

Figure $2.8 \quad$ Photograph of Plexiglass containment enclosure $\ldots \ldots \ldots \ldots \ldots \ldots \ldots \ldots$

Figure 2.9 Photograph of enclosure during smoke bomb leak test $\ldots \ldots \ldots \ldots \ldots \ldots$

Figure 3.1 Photograph of concrete debris used during large particle size process testing . . 23

Figure 5.1 ALT leach results for waste forms containing $50 \mathrm{wt} \%$ RFETS salt surrogate . . 33 


\section{LIST OF TABLES}

Table 3.1 Salt concentrate composition based on RFETS characterization data . . . . . 12

Table 3.2 Summary of kinetic mixer test sequences to determine effect of moisture content on processing using LDPE $(50 \mathrm{MI}), 1 \mathrm{~kg}$ batch size $\ldots \ldots \ldots \ldots \ldots \ldots$

Table 3.3 Experiment summary to determine effect of batch size on processing using RFETS salt concentrate at a waste loading of $50 \mathrm{wt} \% \ldots \ldots \ldots \ldots \ldots$

Table 3.4 Processing results for polymer type comparison with $50 \mathrm{wt} \%$ waste surrogate

Table 3.5 Comparison of extrusion and kinetic mixing polyethylene product densities . . 18

Table 3.6 Summary of moisture removal experiments with LDPE (22 MI) and $50 \mathrm{wt} \%$ salt

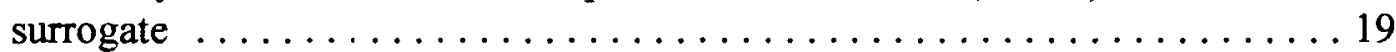

Table 3.7 Summary of moisture removal experiments with LDPE (22 MI) and $50 \mathrm{wt} \% \mathrm{BNL}$ soil

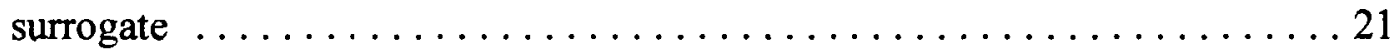

Table 3.9 Summary of recycled plastics investigated for microencapsulation . . . . . . 25

Table 3.10 Testing conditions and product density results for R-LDPE (JAM Plastics) . . . 26

Table 3.11 Testing conditions and product density results for R-HDPE (Clearzon IM8) . . 27

Table 3.12 Testing conditions and product density results for recycled HDPE (Forrester) . 27

Table 4.1 Processing results for kinetic mixer confirmation testing with 50 weight percent nonradioactive and radiologically contaminated $\mathrm{BNL}$ soil $\ldots \ldots \ldots \ldots \ldots \ldots$

Table $5.1 \quad$ Compressive strength of recycled plastic waste forms . . . . . . . . . . 32

Table 5.2 TCLP leach results for LDPE waste forms with $50 \mathrm{wt} \% \mathrm{BNL}$ soil spiked with 5000

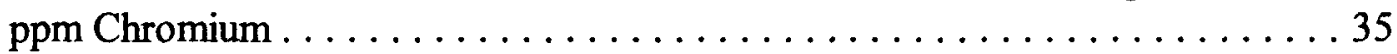

Table 5.3 Compressive strengths of LDPE waste forms with $50 \mathrm{wt} \%$ BNL soil $\ldots \ldots \ldots 36$ 



\subsection{INTRODUCTION}

The objective of this effort was the development and demonstration of kinetic mixing as an improved process for polyethylene microencapsulation of mixed wastes. Sponsorship was provided by the U.S. Department of Energy (DOE) EM-50 Mixed Waste Focus Area (MWFA) and EcoLEX, Inc., Burlington, Ontario, which provided equipment and engineering assistance under a Cooperative Research and Development Agreement (CRADA). The use of polyethylene for waste solidification has wide application to different waste types and is a viable treatment alternative for DOE low-level mixed wastes as well as hazardous and low-level radioactive wastes. Processing wastes with polyethylene has been developed using extrusion [1], a versatile, industry-proven technology. Advantages of polyethylene microencapsulation by extrusion have been well documented. $[2,3,4,5,6,7,8,9,10,11,12]$ However, successful extrusion processing of wastes containing moisture and/or organic content greater than approximately $2 \mathrm{wt} \%$, requires thermal pre-treatment of the waste. Successful extrusion processing can also be limited by the waste particle size range. Kinetic mixing can improve upon these limitations, thereby making the polyethylene microencapsulation process more cost-effective and expanding the applicability of the process to encompass a broader range of waste properties.

To demonstrate kinetic mixing as a viable waste treatment technology, thorough testing was conducted to establish the capabilities of the mixer, operating procedures, and the impact of varying process parameters on overall waste processibility and product appearance and performance. The ability to process wet wastes with moisture contents exceeding those permissible by extrusion $(>2$ $\mathrm{wt} \%)$ and wastes outside acceptable extrusion particle size range $(50 \mu \mathrm{m}$ to $2000 \mu \mathrm{m})$ was investigated. Varying process parameters included batch size, cycle time, waste surrogate type and type of polyethylene. Recycled plastics were also tested for use in this process in place of virgin polyethylene. The ability to successfully process by kinetic mixing is based on consideration of material feed, cycle time, batch repeatability, and product homogeneity, appearance and consistency. Testing results and observations were also used to make process modifications and mixer design changes to enhance the use of kinetic mixing for waste encapsulation. For final process verification, "hot" testing was conducted using "mixed waste" comprised of radioactively contaminated soil containing cesium $\left(\mathrm{Cs}^{137}\right)$ and strontium $\left(\mathrm{Sr}^{90}\right)$ to which the hazardous (Resource Conservation and Recovery Act (RCRA)) metal Cr was added. 


\subsection{BACKGROUND}

\subsection{Polyethylene Microencapsulation}

Polyethylene encapsulation is an innovative thermoplastic solidification treatment method in which waste materials are physically stabilized within a polymer matrix. This is accomplished by heating the thermoplastic above its melting point, then mixing the molten polymer with the waste. Solidification of the encapsulated matrix is assured upon cooling and is independent of the chemical nature of the waste materials. For this reason, polyethylene encapsulation has application to a wide range of waste types and can be used for hazardous, low-level radioactive and low-level mixed wastes.

Mechanically mixing waste materials with a viscous polymer and processing the mixture can be accomplished by the use of extrusion or kinetic mixing. Previous development and demonstration efforts for polyethylene encapsulation have been based on the extrusion process; the focus of this effort is the development and demonstration of kinetic mixing. For extrusion, dry waste and polymer are continuously fed to the extruder feed throat by individual dynamic feeders. Precise control can be maintained by the feeders to accurately meter the polymer and waste material to the extruder and to maintain a constant waste loading. Within the extruder, a variable speed screw mixes the molten polyethylene with the waste material, builds pressure, and pumps the homogeneous mixture through an output die. The extruder product, also known as extrudate, can be collected directly in a waste container. Post-treatment of the product from the extruder is not necessary. Natural cooling of the extruder product results in a solid monolithic waste form suitable for disposal. The processing temperature is controlled through independent temperature zones which can be tailored to achieve a particular temperature profile, depending on the melting point and melt properties, e.g., melt viscosity of the polymer. Low-density polyethylene, as used in this process, has a melting point of approximately $120^{\circ} \mathrm{C}$, so typical extrusion temperatures range from 120 to $160^{\circ} \mathrm{C}$.

Polyethylene encapsulation is purely a physical process and therefore has application to a wide range of different waste types. Chemical reactions are not required for solidification so chemical incompatibilities between the waste and polymer are not a concern, as is the case for competitive waste treatment technologies such as cementation. Extrusion processing is limited by the moisture content and particle size of the wastes. Moisture in excess of approximately $2 \mathrm{wt} \%$ must be removed prior to processing. This is because extruders are not designed for devolatilization. Extruders may be equipped with vent zones to remove small amounts of vaporized gas and to prevent entrained gas in the molten product while processing otherwise dry materials. Wastes with higher moisture contents require thermal pretreatment. The particle size distribution of the waste must not contain an excess of fines with particle sizes less than approximately $50 \mu \mathrm{m}$ since it is difficult to "wet" and mix the fine particles with the viscous melt. The upper particle size limit is dependent on the size of the extruder but an excess of large particles will have a deleterious impact on waste form leachability. Performance of polyethylene waste forms has been thoroughly investigated $[2,6,7,10,12]$ and, in general, is well above minimum requirements specified by the Nuclear Regulatory Commission (NRC) [13,14] and the Environmental Protection Agency (EPA). [15] Polyethylene waste forms have been 
judged to be extremely durable under anticipated storage and disposal conditions by evaluating potential failure mechanisms, e.g., exposure to high radiation doses, microbial degradation, harsh chemical environments and extremes in temperature.

Polyethylene encapsulation has been successfully applied to treat aqueous evaporator concentrates (nitrates, chlorides, sulfates, borates), sludges, blowdown solutions, molten salt oxidation spent salts, soils and soil washing residues, incinerator fly ash and bottom ash, and ion exchange resins. Extrusion processing with some of these wastes requires pretreatment. Kinetic mixing was investigated during this effort in order to enhance the capabilities of polyethylene microencapsulation by reducing the necessity or extent for waste pretreatment by either thermal drying or size reduction.

\subsection{Kinetic Mixing Process and Equipment Description}

Kinetic mixing is a batch polymer processing technique that uses high shear and rapid rotational motion to create frictional heat sufficient to volatilize moisture and melt thermoplastics. Polymer and waste are fed to the mixer feed throat batch-wise, rapidly brought to melt temperature, and mixed, then discharged as a thoroughly homogenized molten mass. The product may be suitable for final disposal or secondary treatment (e.g., extrusion or compression molding) may be necessary. As with extrusion processing, solidification of the product is assured on cooling. The robust agitation and mixing action potentially makes kinetic processors less sensitive to particle size limitations and permits a higher tolerance for moisture. Due to the design of the mixer, moisture can be vaporized throughout a batch cycle as frictional heat is used to overcome the latent heat of vaporization. Friction is generated through shear between the mixing blades and the mixing chamber wall and by particle to particle contact. Cycle time is dependent upon the feed composition, batch size and moisture content. Abrasive materials and increasing the batch size will decrease cycle time due to increased friction. Wastes containing a higher moisture content require additional cycle time since frictional heat will be used to vaporize the moisture. This technology may improve the costeffectiveness of polyethylene encapsulation by reducing waste pretreatment needs and is also an ideal candidate for substituting various polymers such as recycled plastics because the feed materials can be altered on a batch-to-batch basis with minimal modification to the operating procedure. The operating temperature of the mixer is not pre-set so materials will melt and mix following sufficient kinetic energy generation. For example, substituting a thermoplastic with a higher melting point will simply require a slightly longer cycle time. The use of recycled plastics in the kinetic mixer would reduce operating costs due to their lower cost, thereby reducing process feed material costs.

Feasibility testing with waste surrogates and recycled plastics was conducted using a pilotscale kinetic mixer rated at approximately $450 \mathrm{~kg} / \mathrm{hr}(1000 \mathrm{lb} / \mathrm{hr})$. The mixer was manufactured by LEX Technologies, Brampton, Ontario, Canada and was supplied by EcoLEX, Inc of Burlington, Ontario. The mixer consists of a $10 \mathrm{~L}$ batch mixing chamber, helical screw feed section, $7 \mathrm{~cm}$ rotating shaft with six mixing paddles, water cooled bearings, and pneumatically controlled inlet gate and discharge door. The shaft, powered by a $150 \mathrm{HP}$ electric motor, rotates at a constant speed resulting in a paddle tip speed of approximately $40 \mathrm{~m} / \mathrm{sec}$. Operation is controlled by a 
programmable logic controller (PLC), enabling the operator to coordinate feeding, charging, mixing and discharging of the materials. Charge and discharge functions can be automated based on motor load sensing (ammeter), a temperature probe signal, or pre-determined time intervals. Alternatively, these functions can be manually controlled by the operator.

The kinetic mixer used during this effort was not equipped with a temperature sensor so appropriate cycle times to successfully process each batch were determined based on the motor load or audible vibrations. At the completion of a cycle, the polymer "fluxes" by melting and mixing with the filler or waste materials. This point can usually be discerned because the molten polymer and waste now move as a single large mass within the mixing chamber resulting in an uneven load on the drive motor. The result is an increased load upon fluxing and vibrations in the mixer. Figure 2.1 is a sketch of the pilot-scale kinetic mixer. A photograph of the kinetic mixer after installation at BNL is shown in Figure 2.2.

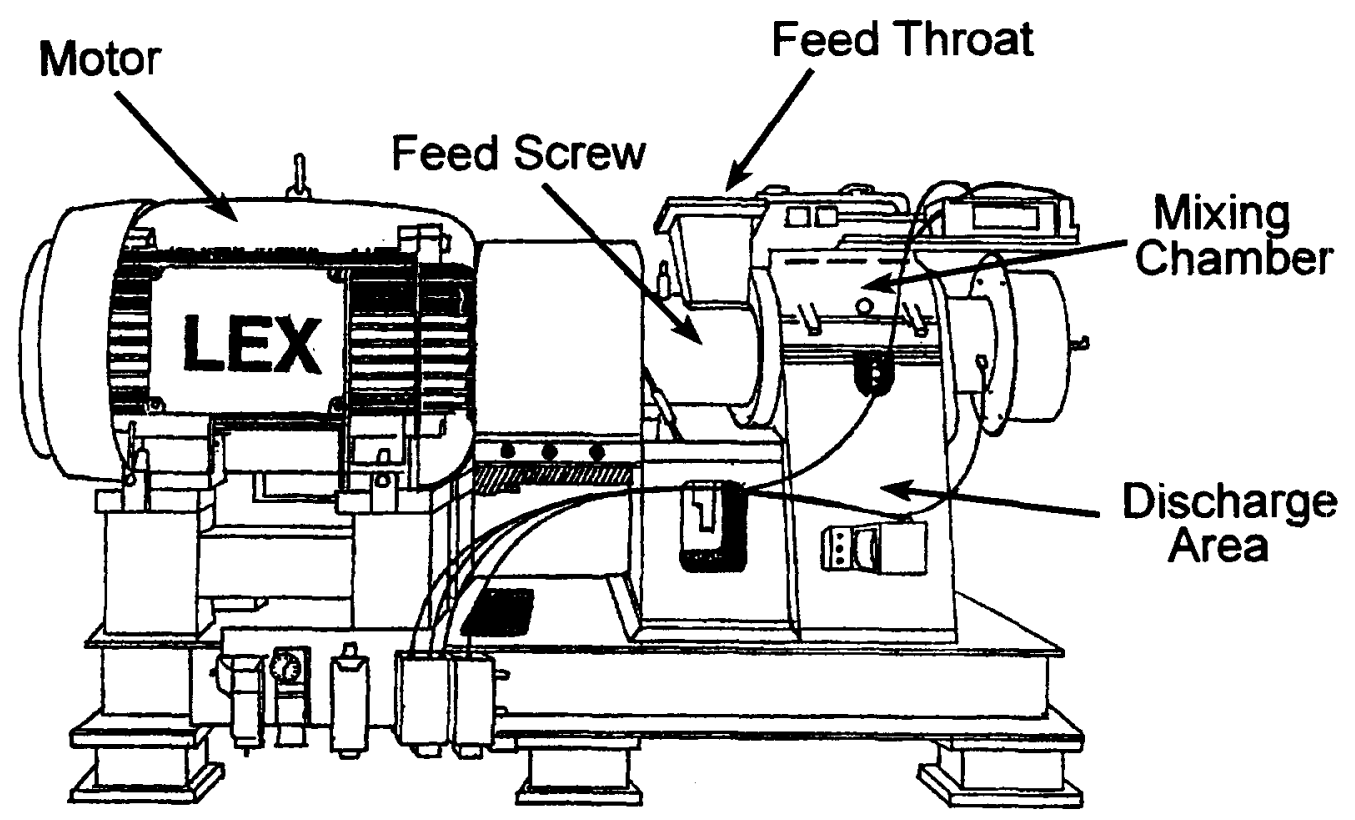

Figure 2.1 Sketch of the pilot-scale kinetic mixer 


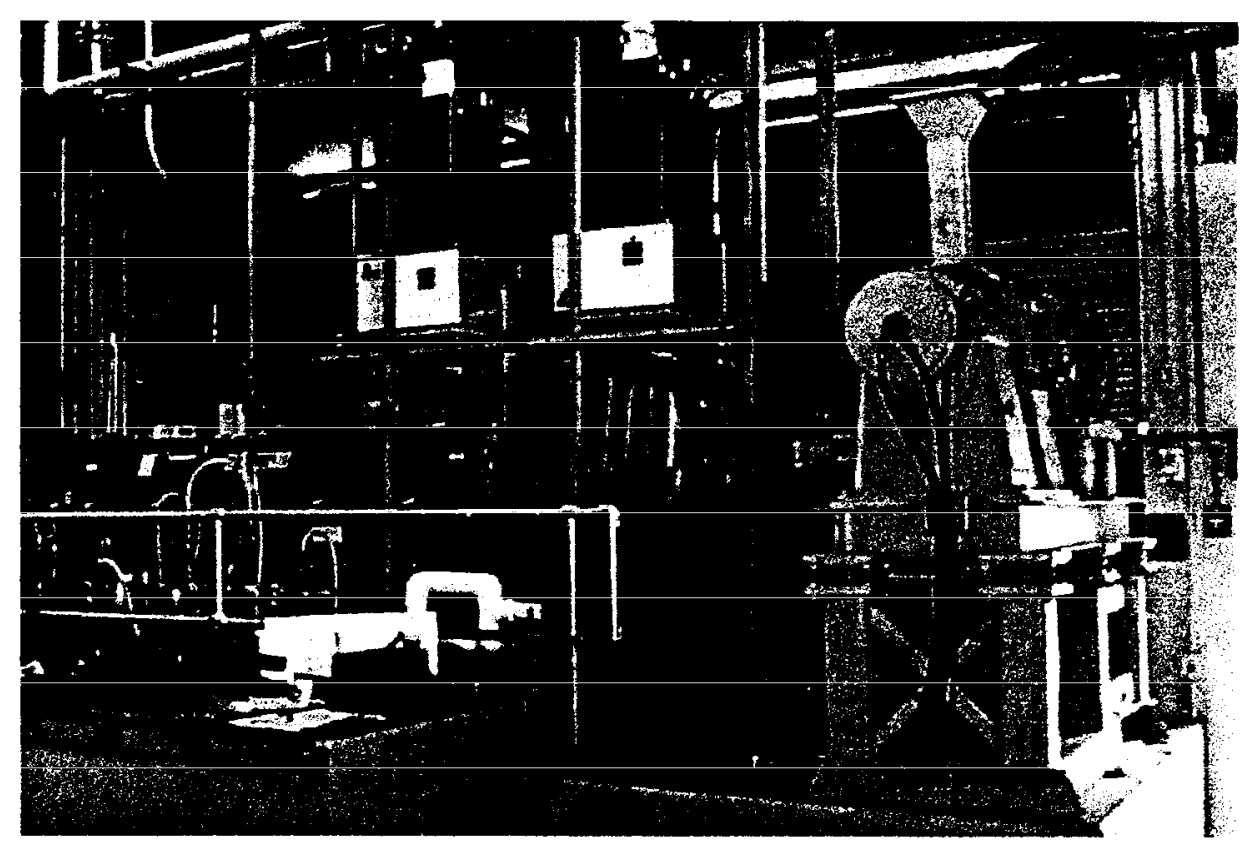

Figure 2.2 Photograph of kinetic mixer after installation at BNL

\subsection{Kinetic Mixer System Modifications and Improvements}

Kinetic mixers are used conventionally for plastics processing and compounding applications, i.e., mixing fillers, colorants and/or additives with polymers. The advantage of kinetic mixers for plastic processing stems from the ability to vary batch composition including polymer type, polymer grade, filler material and filler loading on a batch-to-batch basis with little or no system and/or parameter modification. Capital equipment cost is also low for kinetic mixers compared with alternative processing methods (e.g., Banbury mixers, single-screw extruders, twin-screw extruders, or continuous mixers) with equivalent processing capacities. [16] Application of stock processing equipment, like the kinetic mixer, for new uses not included in original engineering design often results in specific technical deficiencies. During process development work, modifications were made to the kinetic mixer to enhance waste processing and permit the processing of actual hazardous and/or radioactive wastes. Kinetic mixer modifications included a new feed tube and feed gate, installation of vent ports for an off-gas collection system, and repair of the mixing blades. System improvements included the erection of a steel superstructure around the kinetic mixer, design and construction of an off-gas collection system and fabrication of a containment enclosure.

The first mixer modification was replacement of the original feed tube and feed gate mechanism. The original feed tube was constructed of a rigid steel structure and fitted with a slide gate to control batch charging. A photograph of the kinetic mixer following initial installation at BNL was shown in Figure 2.2. The kinetic mixer, rated at $450 \mathrm{~kg} / \mathrm{hr}(1000 \mathrm{lb} / \mathrm{hr})$, is shown in the right portion of the photograph. On the left is a $900 \mathrm{~kg} / \mathrm{hr}(2000 \mathrm{lb} / \mathrm{hr})$ single-screw extruder. The steel 
feed tube is clearly visible as the vertical protrusion above the kinetic mixer. The feed tube was replaced because difficulties were encountered while processing surrogate materials with elevated moisture levels due to bridging of these feed materials in the feed throat. Specific feeding difficulties were observed during initial shakedown testing while processing a nitrate salt surrogate at moisture levels of 9 and 17 weight percent (wt\%). At these moisture contents, the nitrate salt surrogate had a salt cake consistency and readily clumped. Attempting to process the salt surrogate under these conditions was unsuccessful. An additional problem with the steel feed tube was the tendency to disperse dry materials around the slide gate mechanism. To alleviate these problems, EcoLEX engineers designed a modification to the mixer feed system. The standard rigid steel feed throat and corresponding slide gate used to control charging of feed materials to the mixer was replaced with a new feed throat assembly. The replacement feed throat, built by LEX and installed with the assistance of an EcoLEX representative, was comprised of a flexible Neoprene boot with a pneumatically operated pinch valve as shown in Figure 2.3. This new design provided a dramatically improved seal to eliminate the possibility for material dispersion during feeding, an important consideration for radioactive material processing. The function of the flexible feed tube was to alleviate feeding difficulties by transmitting mixer vibrations which would minimize the accumulation of materials on the wall of the feed tube. Feeding difficulties were reduced, but occasional clogging and bridging of wet feed materials occurred below the feed tube in the area immediately above the feed screw used to convey materials into the mixing chamber. This problem was observed only in a small range of moisture contents but could not be remedied with the current mixer design.

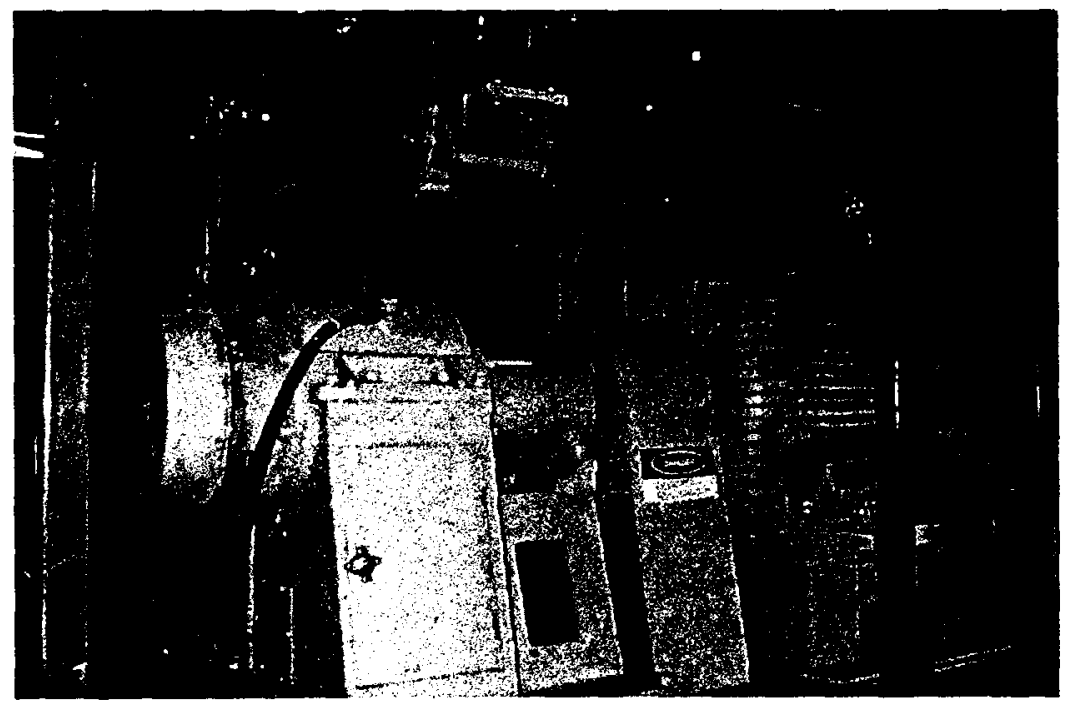

Figure 2.3 Kinetic mixer installed at BNL with modified feed tube.

The as-received LEX mixer was not equipped with any off gas collection capability necessary for application to microencapsulation of mixed waste. Thus, BNL designed and constructed an off 
gas system to collect and contain vaporized gases and moisture. A schematic diagram of the off gas system components is shown in Figure 2.4. The process chamber was modified with two ventilation ports to accommodate the off gas system. The outboard end of the mixer was disassembled and the outer mixing chamber wall and end flange removed. Two 0.5 inch $(1.3 \mathrm{~cm})$ vent ports were drilled through the hard-facing on the mixing chamber wall and through the end flange by the BNL machine shop. The ports originated near the centerline of the mixing shaft. Off gases flow through steel mesh filters to reduce carryover and are then plumbed to a jacketed copper condensation coil that uses countercurrent flow-through water cooling as a heat exchange medium. Condensed vapors are collected in a 16.5 liter Lucite collection vessel. Off gas is then drawn through a liquid nitrogen trap, prefilter, HEPA filter and activated carbon bed. Vacuum is provided by a $41 \mathrm{ft}^{3} / \mathrm{min}(116 \mathrm{l} / \mathrm{min})$ vacuum pump. The system is fitted with three pressure gauges to monitor potential pressure drops due to plugging or leaking. Figure 2.5 is a photograph of the kinetic mixer off gas system. The condensation coil, Lucite condensate collection vessel, and rectangular HEPA filter box are clearly discernable in the photograph.

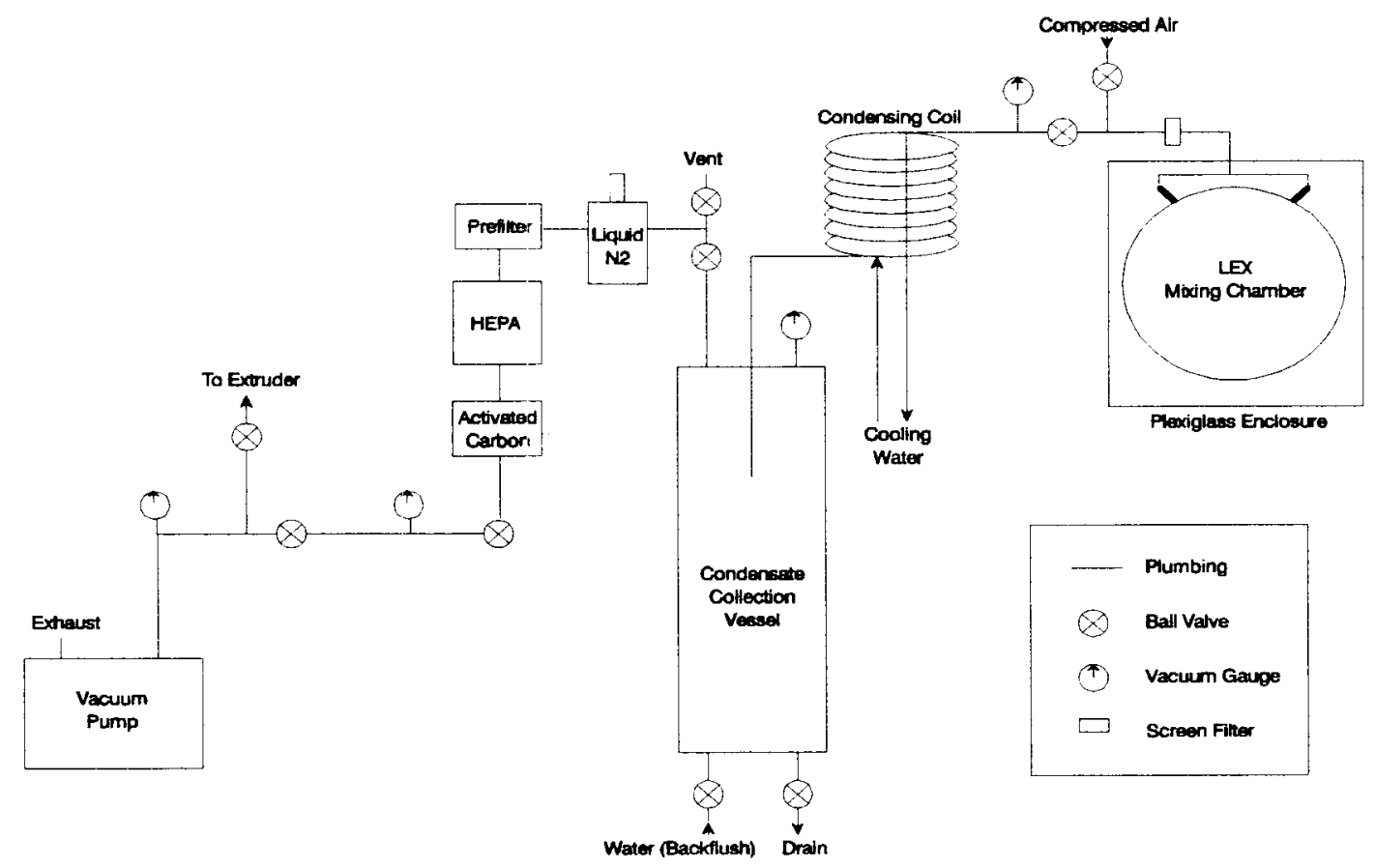

Figure 2.4 Schematic of kinetic mixer off gas system. 


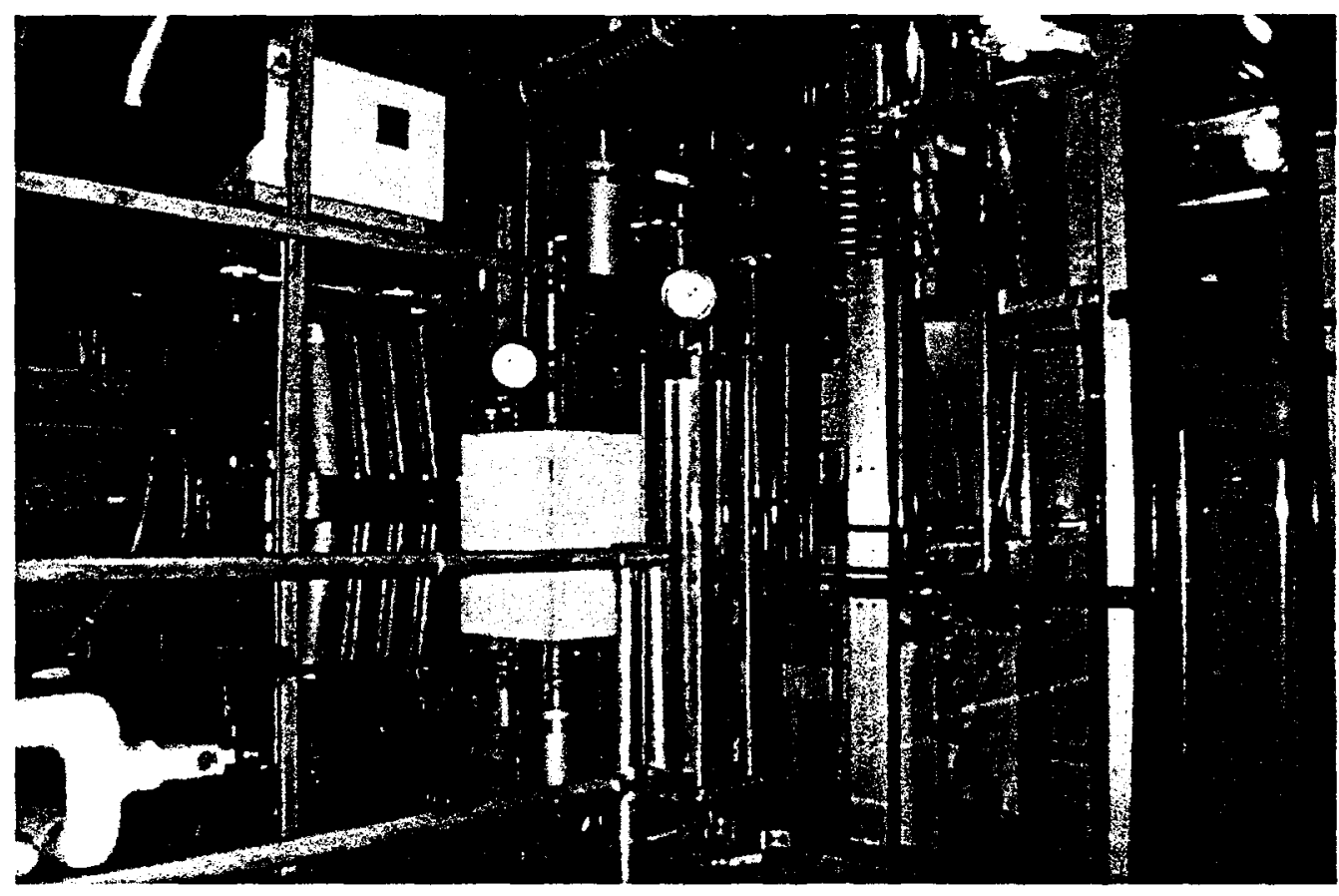

Figure 2.5 Photograph of kinetic mixer off gas system.

Repairs were made to the mixing blades to improve processing. General maintenance for kinetic mixers requires the periodic rebuilding of the mixing blades which gradually wear by abrasion. The mixing blades are initially fabricated from steel and are coated with hard facing such as Stellite. Repair involves the removal of the outboard flange end of the mixer in order to access the mixing blades which are mounted on a sleeve that slides off from the main mixing shaft. The mixing blades on the EcoLEX kinetic mixer were repaired in this manner. Weld was used to increase blade length to original design specifications. Then, hard-facing (Stellite) was applied to the leading edges of the mixing blades. Dramatic improvements in kinetic mixer operation were noted upon repair of the mixing blades. Cycle times decreased significantly due to the increased shear generated by the improved tolerance between the mixing blades and the mixing chamber wall. Photographs showing the kinetic mixer with the end flange removed for access to the mixing blades and the mixing blade sleeve are shown in Figures 2.6 and 2.7, respectively.

System modifications included the construction of a steel superstructure necessary to support a material feed system above the kinetic mixer. This superstructure was later used as a foundation for the fabrication of a containment enclosure. The enclosure, shown in Figure 2.8, was fabricated from Plexiglass. The purpose of the enclosure was to contain the mixer operations and in conjunction with a HEPA ventilation system prevent accidental dispersion or release of hazardous and radiological material while processing mixed wastes. A thorough safety and design review of the enclosure was conducted by the BNL Department of Advanced Technology (DAT) Safety Committee. Review 
comments were addressed and incorporated into the enclosure design. Construction of the enclosure was completed just prior to feasibility processing with mixed wastes. A leak test was conducted on the enclosure by igniting several smoke bombs within the enclosure to ensure complete containment and proper ventilation. A photograph of the enclosure leak test is shown in Figure 2.9. Mixed waste processing also required the preparation of a comprehensive experimental safety plan detailing the equipment design, operation, safety features, potential hazards, hazard mitigation methods and experimental procedure. This report was prepared in accordance with BNL Environmental Safety and Health guidelines (BNL ES\&H 1.3.5).

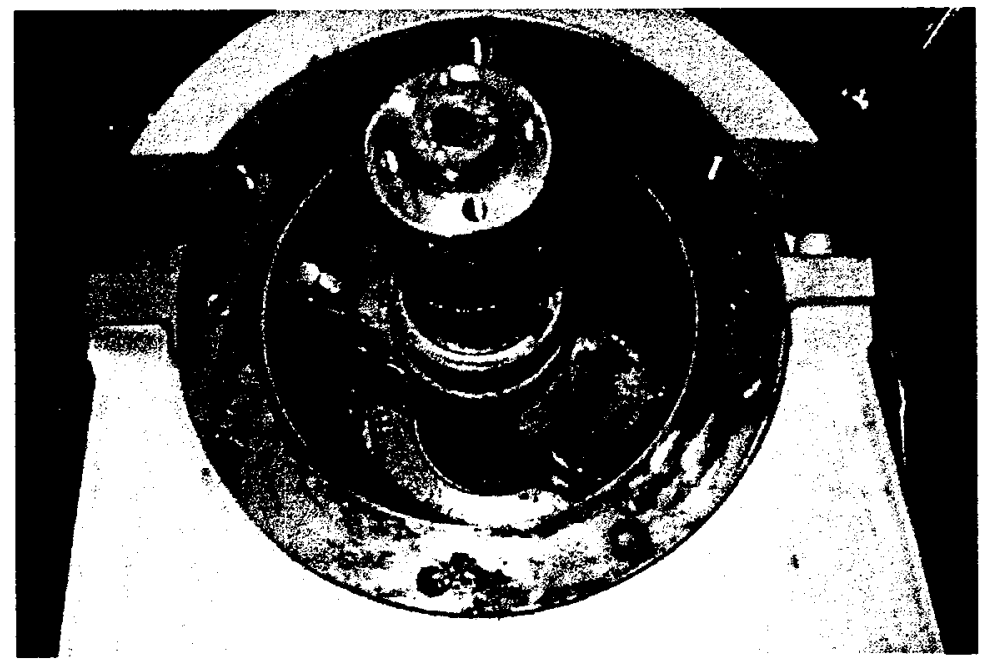

Figure 2.6 Photograph of kinetic mixer with end flange removed for access to mixing blades.

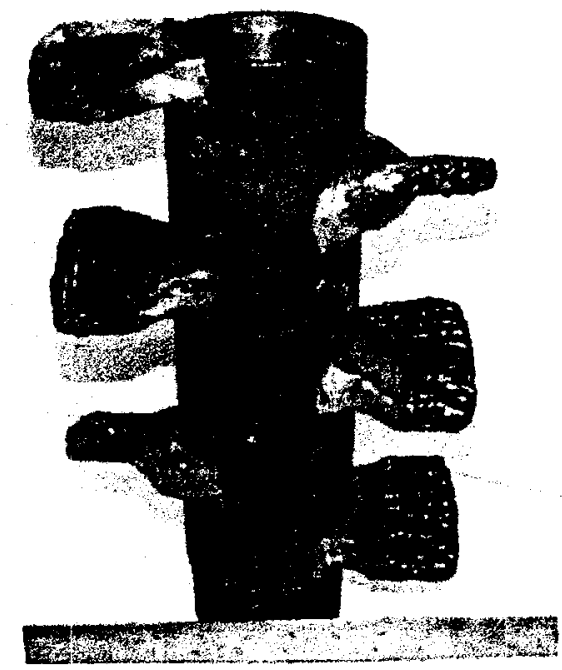

Figure 2.7 Photograph of mixing blade sleeve. 


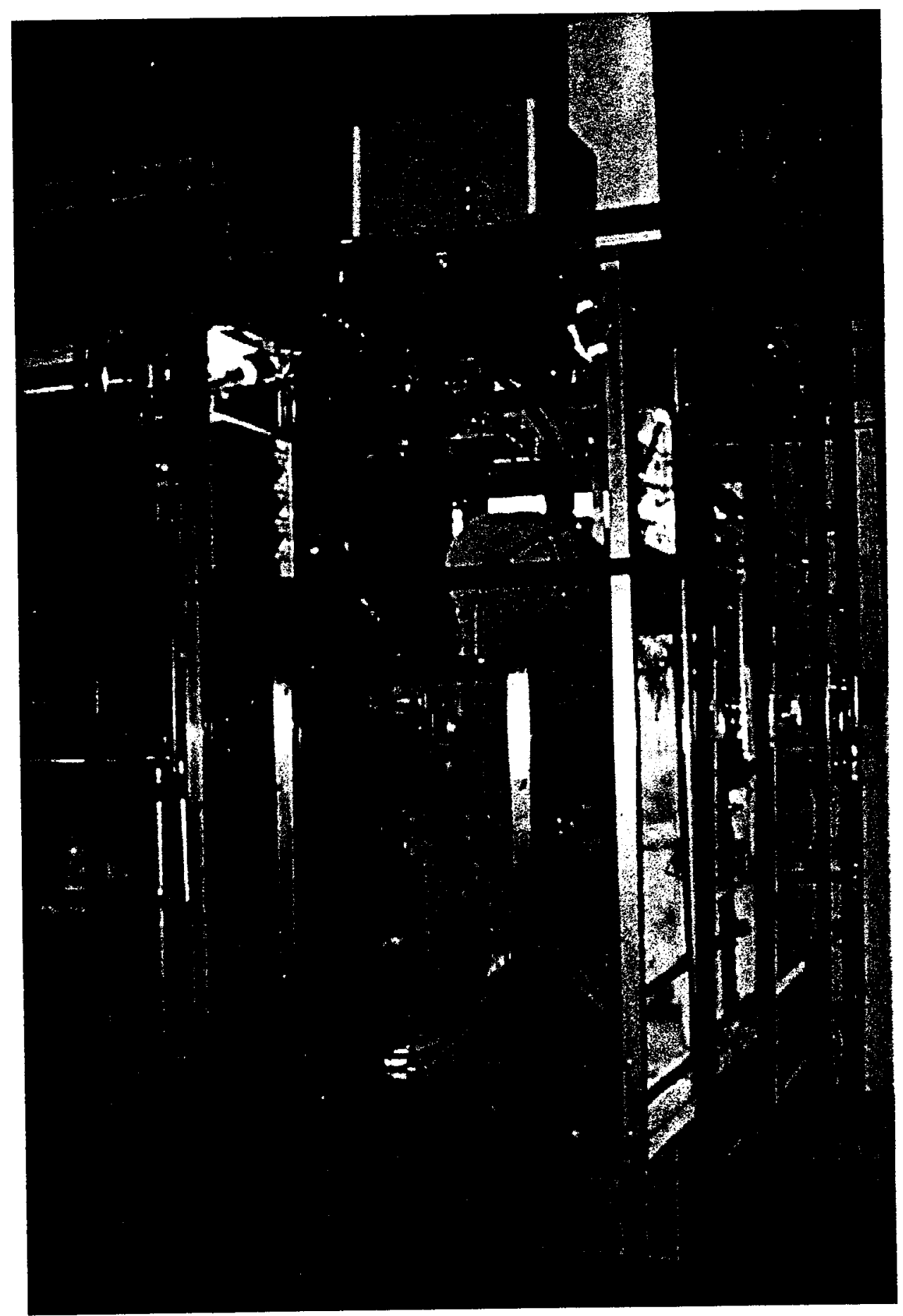

Figure 2.8 Photograph of Plexiglass containment enclosure. 


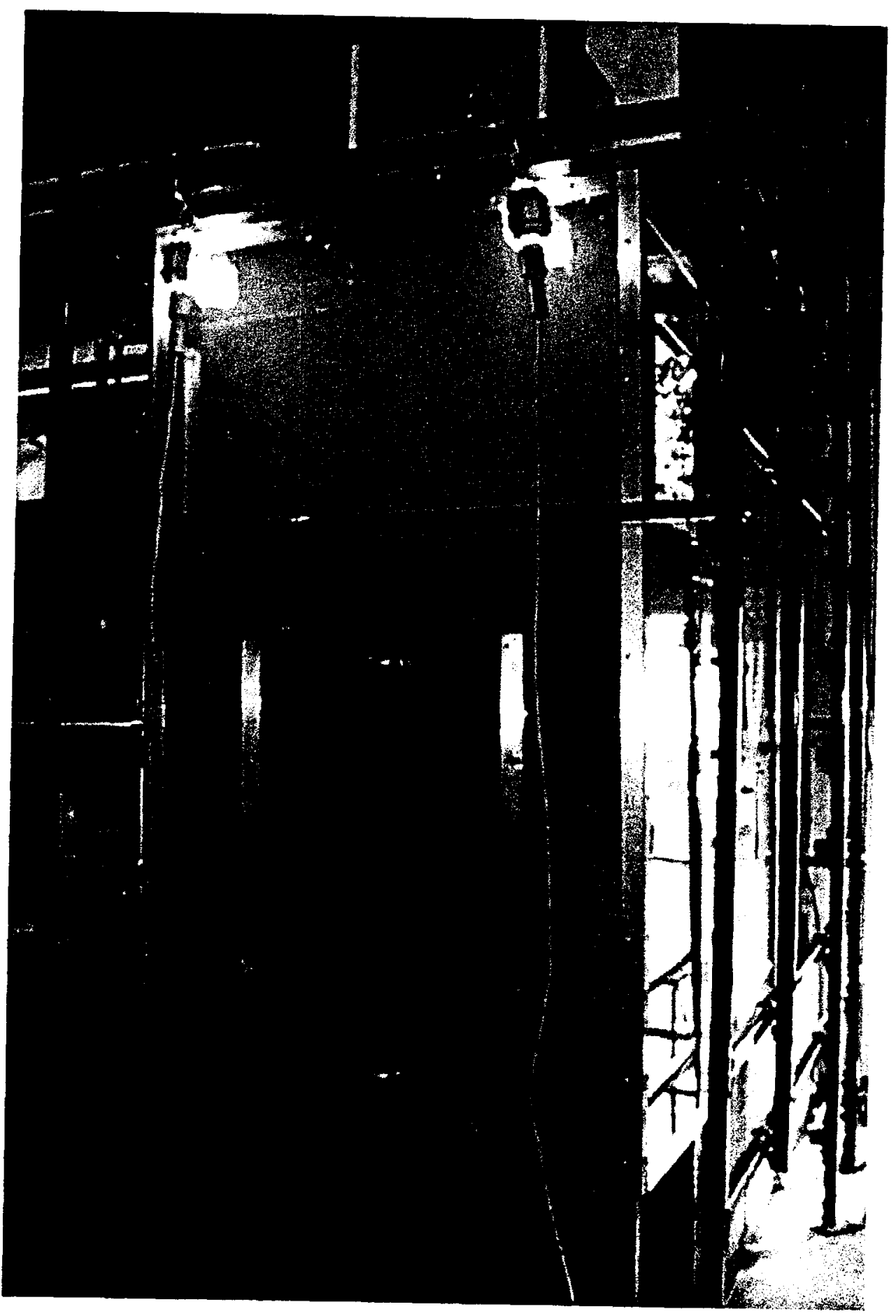

Figure 2.9 Photograph of enclosure during smoke bomb leak test. 


\subsection{PROCESS DEVELOPMENT AND TESTING}

The primary objective of this effort was to evaluate the feasibility of using kinetic mixing as a stand-alone processing system for polyethylene microencapsulation. Prior to this effort, the application of kinetic mixers to waste encapsulation had not been considered. Their primary function was in the plastics industry for compounding or processing plastic blends including recycled plastics. The robust design of kinetic mixers showed promise to reduce the demand for thermal pretreatment and size reduction of wastes often necessary for extrusion-based polyethylene microencapsulation.

The development of kinetic mixing for polyethylene microencapsulation consisted of initial testing to ascertain the impact of varying process parameters on operation followed by specifically designed tests to determine the capabilities of the mixer. Most significant was the ability of the kinetic mixer to process wastes containing elevated moisture levels and wastes with large particle size distributions. These are the two areas that could potentially result in performance and cost savings over waste encapsulation by extrusion processing. Experiments were divided into test sequences usually consisting of between 5 to 10 replicate batches. Process parameters varied include polymer type (e.g., low-density polyethylene, high-density polyethylene, polypropylene), polymer grade (e.g., melt index and molecular weight distribution) batch size, waste moisture content and waste type. The number of process parameters varied per test sequence was minimized to simplify evaluation of data. Different wastes have varying physical attributes such as particle size and abrasiveness which affect processing. During development testing, the polymer type was primarily limited to low-density polyethylene except during later investigations on the impact of recycled plastics on waste processing. The results of recycled plastics processing are discussed in Section 3.4, Recycled Plastic Processing. The materials used as wastes during this development work were waste surrogates for aqueous salt concentrates and contaminated soil.

The aqueous salt concentrate surrogate was prepared at BNL during development work for the Polyethylene Encapsulation Full-Scale Technology Demonstration [10] according to characterization data from the Rocky Flats Environmental Technology Site (RFETS). The original evaporator aqueous concentrate was a salt solution containing $35 \mathrm{wt} \%$ dissolved solids. The composition of salts is summarized in Table 3.1. This surrogate represents high-volume salts wastes produced by the neutralization of acids used in the spent fuel reprocessing, uranium purification/enrichment, ion exchange resin regeneration, and high-level waste treatment. For this study dry salts were hydrated with varying levels of moisture to examine moisture tolerance of the process. The second waste surrogate used during development work was BNL soil representing high-volume contaminated soils found throughout the DOE complex. The surrogate soil was collected on-site at BNL and screened to remove rocks and organic matter. 
Table 3.1 Salt concentrate composition based on RFETS characterization data.

\begin{tabular}{||l|l|l|}
\hline Compound & Chemical Formula & Composition (wt\%) \\
\hline \hline Sodium nitrate & $\mathrm{NaNO}_{3}$ & 37.3 \\
\hline Sodium sulfate & $\mathrm{Na}_{2} \mathrm{SO}_{4}$ & 17.7 \\
\hline Sodium fluoride & $\mathrm{NaF}$ & 5.2 \\
\hline Potassium chloride & $\mathrm{KCl}$ & 31.6 \\
\hline Magnesium chloride & $\mathrm{MgCl}_{2}$ & 2.0 \\
\hline Calcium carbonate & $\mathrm{CaCO}_{3}$ & 6.2 \\
\hline
\end{tabular}

\subsection{Initial Testing}

Initial testing on the kinetic mixer was performed in early FY97 following successful mixer installation and shakedown testing. The focus of initial testing was to gauge the influence of varying process parameters on the mixer operation. To accomplish this, a series of test sequences were conducted using a constant waste surrogate loading of 50 weight percent while varying the waste surrogate type, moisture content and batch size. The polymer types used were low-density polyethylenes with melt indices of 8,22 or $50 \mathrm{~g} / 10 \mathrm{~min}$. .

As mentioned, each test sequence consisted of between 5 and 10 replicate batches in order to ensure data quality and processing repeatability. Feed materials were manually pre-weighed and blended prior to a test sequence. Although the control system for the kinetic mixer permits automated batch cycling which includes feeding materials and discharging the product, the mixer was operated manually since the feed materials were frequently varied during this development effort. The pre-weighed and blended feed materials were manually fed to the mixer feed tube prior to each batch. Cycle time required to flux (melt the polymer and homogeneously mix the waste filler with the molten polymer) were determined based on audible vibrations or by an increased amperage load on the drive motor. Fluxing generally results in a noticeable vibration and load increase because once the polymer melts and mixes, it agglomerates into a single large mass that moves eccentrically around the mixing chamber.

Success or failure of processing at a given set of conditions was based on qualitative observations and quantitative measurements. Qualitative observations were made on the product and on the overall processibility such as product appearance, material feed, material discharge, cycle time and proper flux point detection through either noticeable vibrations or amperage change on the drive motor. Quantitative measurements were used to monitor batch-to-batch consistency and repeatability. This was achieved by measuring product densities, product yield and unencapsulated material yield. Product densities were determined from grab samples removed from the product from each batch within a test sequence. For example, for each test sequence consisting of 10 replicate 
batches, five grab samples were removed from each batch product. One grab sample was then selected randomly from each of the 10 replicate batches. Densities were calculated by weighing each grab sample and measuring the volume using a Quantachrome Multipycnometer. The reported density is an average of the 10 replicates.

In general, the fluxed product discharged from the kinetic mixer tends to have some poorly encapsulated material on the surface of the molten polymer. This is not observed with extrusion and is purely a result of the design and operation of kinetic mixers. Additionally, depending on the properties of the waste and polymer, some unencapsulated material may be discharged with the fluxed product at batch cycle completion. Both of these problems can be overcome by extruding or compression molding the mixer discharge.

\subsubsection{Effect of moisture content on batch cycle time}

The effect of moisture content on batch cycle time was investigated through a series of test sequences using one polymer and three waste surrogates, and is summarized in Table 3.2. Results indicated increases in cycle time with corresponding increases in waste surrogate moisture content. An increase in cycle time is an expected result since frictional heat generated in the mixing chamber is used to evaporate moisture. All moisture is vaporized prior to the polyethylene melting at approximately $120^{\circ} \mathrm{C}$. At the higher moisture contents, the cycle time was more difficult to discern because amperage changes on the drive motor and vibrations while fluxing were not as noticeable.

For the salt concentrate at $50 \mathrm{wt} \%$ loading, the cycle time increased from $20 \mathrm{sec}$ for $1 \mathrm{~kg}$ batches with $5 \mathrm{wt} \%$ moisture to over 2 minutes for batches containing approximately $23 \mathrm{wt} \%$ moisture. Similar trends were noted with the soil and sand surrogates. This testing highlighted kinetic mixer design limitations that affected waste surrogate processibility. The salt concentrate at moisture contents of 10 and $16.7 \mathrm{wt} \%$ had a tendency to clump and cake together. While feeding, the salts clogged and bridged the feed throat over the feed screw. The mixer relies on a feed screw to convey materials from the feed throat into the mixing chamber. This difficulty along with subsequent feeding problems with wet salts prompted the feed tube modification described previously. At a moisture content of $23 \%$ for the salt concentrate, leakage of liquid occurred around the discharge gate seal. Feeding difficulties were not encountered with the soil and sand surrogates, however, appropriate cycle times to achieve the correct flux point were difficult to discern. 
Table 3.2 Summary of kinetic mixer test sequences to determine effect of moisture content on processing using LDPE (50 MI), $1 \mathrm{~kg}$ batch size and waste loading of $50 \mathrm{wt} \%$.

\begin{tabular}{|c|c|c|c|}
\hline Waste Surrogate & $\begin{array}{l}\text { Moisture Content } \\
\text { of Surrogate }\end{array}$ & Cycle Time & Results \\
\hline salt concentrate ${ }^{\mathbf{a}}$ & 5 & $20 \mathrm{sec}$ & Processed well \\
\hline salt concentrate & 10 & $\mathrm{n} / \mathrm{a}$ & Salts clogged feed throat \\
\hline salt concentrate & 16.7 & $\mathrm{n} / \mathrm{a}$ & Salts clogged feed throat \\
\hline salt concentrate & 23.1 & $2 \mathrm{~min} 5 \mathrm{sec}$ & $\begin{array}{l}\text { Fed and processed well but liquid leakage } \\
\text { from discharge gate }\end{array}$ \\
\hline soil $^{\mathrm{b}}$ & 6 & $15 \mathrm{sec}$ & Processed well \\
\hline soil & 10 & $30 \mathrm{sec}$ & Fed well. Cycle times difficult to discern \\
\hline soil & 15 & $\mathbf{n} / \mathbf{a}$ & $\begin{array}{l}\text { Fed well. Cycle times very difficult to } \\
\text { discern }\end{array}$ \\
\hline sand $^{\mathrm{c}}$ & 3 & $17 \mathrm{sec}$ & Processed well. \\
\hline sand & 10 & $40 \mathrm{sec}$ & $\begin{array}{l}\text { Processed well but cycle times a little difficult } \\
\text { to discern }\end{array}$ \\
\hline sand & 15 & $55 \mathrm{sec}$ & $\begin{array}{l}\text { Processed well but cycle times a little difficult } \\
\text { to discern }\end{array}$ \\
\hline
\end{tabular}

a dried aqueous salt concentrate based on RFETS characterization data

${ }^{b}$ BNL soil screened to remove organic debris

' generic sand with mixed particle size

\subsubsection{Effect of batch size on cycle time}

The effect of batch size on cycle time was investigated using two types of polyethylene, one waste surrogate and three moisture contents. The total batch size is limited by the size of the kinetic mixer, specifically the volume of the mixing chamber. The kinetic mixer used during this development effort was a LEX 100 with an output capacity rated at $450 \mathrm{~kg} / \mathrm{hr}(1000 \mathrm{lb} / \mathrm{hr})$. This rating capacity is based on processing dry materials and decreases with increasing moisture content since longer cycle times are necessary to flux. Therefore, as the waste moisture content increases, the mixer output capacity decreases. For this mixer, batch size can vary between a minimum of $1 \mathrm{~kg}$ and a maximum of $3 \mathrm{~kg}$. Results of cycle times for different batch sizes are shown in Table 3.3. Testing showed a decrease in cycle time with larger batch sizes. This is caused by increased particle to particle contact and therefore increased frictional heat generation. At $10 \mathrm{wt} \%$ moisture, the wet salts clumped then clogged and bridged the feed screw in the feed throat as previously described. Leakage was also observed around the discharge gate seal while processing at $20 \%$ moisture content with 2 or $3 \mathrm{~kg}$ batch sizes. This leakage is partially accountable for the difference in cycle times for the experiments at $20 \%$ moisture. The more significant the leakage, the less moisture remaining in the mixing chamber that will need to be driven off by frictional heat. The result is shorter the cycle times. No leakage occurred with the $1 \mathrm{~kg}$ batch size which had a cycle time of over 9 minutes. 
Table 3.3 Experiment summary to determine effect of batch size on processing using RFETS salt concentrate at a waste loading of $50 \mathrm{wt} \%$.

\begin{tabular}{||l|c|c|l|l||}
\hline \multicolumn{1}{|c|}{ Polymer } & $\begin{array}{c}\text { Moisture Content } \\
\text { of Surrogate }\end{array}$ & Batch Size & \multicolumn{1}{|c|}{ Cycle Time } & \multicolumn{1}{|c|}{ Results } \\
\hline \hline LDPE (50 MI) & 5 & 1 & $22 \mathrm{sec}$ & Processed well \\
\hline LDPE (50 MI) & 5 & 2 & $17 \mathrm{sec}$ & Processed well \\
\hline LDPE (50 MI) & 10 & 1 & $\mathrm{n} / \mathrm{a}$ & Salts clogged feed throat \\
\hline LDPE (50 MI) & 10 & 2 & $\mathrm{n} / \mathrm{a}$ & Salts clogged feed throat \\
\hline LDPE (22 MI) & 20 & 1 & $\begin{array}{l}\text { up to } 9 \text { min } 20 \\
\mathrm{sec}\end{array}$ & Long cycle time \\
\hline LDPE (22 MI) & 20 & 2 & $4 \mathrm{~min}$ & $\begin{array}{l}\text { Liquid leakage from discharge } \\
\text { gate }\end{array}$ \\
\hline LDPE (22 MI) & 20 & 3 & $2 \mathrm{~min}$ & $\begin{array}{l}\text { Liquid leakage from discharge } \\
\text { gate }\end{array}$ \\
\hline
\end{tabular}

${ }^{a}$ low-density polyethylene with a melt index of $50 \mathrm{~g} / 10 \mathrm{~min}$.

${ }^{b}$ low-density polyethylene with a melt index of $22 \mathrm{~g} / 10 \mathrm{~min}$.

\subsubsection{Comparison polyethylene melt indices}

A comparison of low-density polyethylenes with melt indices of 8,22 and $50 \mathrm{~g} / 10 \mathrm{~min}$ was conducted to determine which polymer provided optimal processibility in the mixer for encapsulation. The melt index refers to ASTM standard D-1238, a measurement of polymer melt flow. The test uses a vertical capillary rheometer to measure the flow of molten polymer under a given load at one shear stress. Melt index (MI) units are given as grams of polymer that flow through a small die in a 10 minute time interval. Therefore, the higher the melt index the greater the melt flow and the lower the melt viscosity. For microencapsulation, a high melt flow is desirable to facilitate waste particle surface wetting and mixing.

Table 3.4 summarizes processing results with the three polyethylenes with both the RFETS salt and the BNL soil surrogate. The waste surrogates were dry with no added moisture. The higher melt flow polyethylenes ( 22 and 50 melt index) processed with comparable cycle times for both waste surrogates. The 8 melt index polyethylene required longer cycle times and resulted in a qualitatively poorer product. More unencapsulated surrogate was discharged with the 8 melt index polyethylene than with the higher melt flow polyethylenes. Polymer viscosity is temperature and shear dependent so longer cycle times, which result in increased shear and temperature, decrease the polymer viscosity. This affected the 8 and 50 MI polyethylenes. Longer cycle times were required for the 8 MI polyethylene in order to decrease the melt viscosity and promote mixing. However, for the 50 MI polyethylene, the cycle times had to be closely monitored because excessive cycle times resulted in the polymer becoming sticky and coating the mixing chamber walls due to the significantly decreased melt viscosity. Cycle times were easiest to control for the $22 \mathrm{MI}$ polyethylene. 
The product densities for each of the three polyethylenes were measured with each waste surrogate at a loading of $50 \mathrm{wt} \%$, as shown in Table 3.4. All batches demonstrated excellent batchto-batch and product consistency as evidenced by the low percent errors. For the BNL soil surrogate, the averages of the main product yield and the yield of unencapsulated material are reported. Each batch discharged from the kinetic mixer typically includes a large molten mass, identified as the main product, along with a small fraction of unencapsulated material. The yields were calculated by weighing the main product and the quantity of unencapsulated material collected following each batch. The yields were based on the mass of surrogate in a batch. It was not possible to close a mass balance on the kinetic mixer on a batch-to-batch basis because collection of all discharged material was not complete. Some material tended to disperse upon cycle completion. It is obviously prudent to minimize the percentage of unencapsulated material. The $22 \mathrm{MI}$ polyethylene maximized the main product yield and had the lowest unencapsulated material yield. Therefore, considering the processing characteristics, cycle time, product density, main product yield and unencapsulated material yield, the $22 \mathrm{MI}$ polyethylene was selected as optimal for microencapsulation using kinetic mixing.

Table 3.4 Processing results for polymer type comparison with $50 \mathrm{wt} \%$ waste surrogate.

\begin{tabular}{||l|l|c|c|l||}
\hline $\begin{array}{c}\text { Polymer } \\
\text { Type }\end{array}$ & Waste Surrogate & Batch Size & Cycle Time & \multicolumn{1}{||}{ Results } \\
\hline LDPE (8 MI) & salt concentrate & 2 & $25 \mathrm{sec}$ & $\begin{array}{l}\text { Product density: } 1.15 \mathrm{~g} / \mathrm{cm}^{3} \text { (1.67\% error). } \\
\text { Some unencapsulated surr. discharged. }\end{array}$ \\
\hline LDPE (22 MI) & salt concentrate & 2 & $18 \mathrm{sec}$ & $\begin{array}{l}\text { Product density: } 1.15 \mathrm{~g} / \mathrm{cm}^{3}(0.65 \% \text { error). } \\
\text { Excellent repeatability. }\end{array}$ \\
\hline LDPE (50 MI) & salt concentrate & 2 & $19 \mathrm{sec}$ & $\begin{array}{l}\text { Product density: } 1.11 \mathrm{~g} / \mathrm{cm}^{3} \text { (1.89\% error). } \\
\text { Product becomes sticky if overheated. }\end{array}$ \\
\hline LDPE (8 MI) & BNL soil & 1 & $52 \mathrm{sec}$ & $\begin{array}{l}\text { Product density: } 1.18 \mathrm{~g} / \mathrm{cm}^{3}(1.67 \% \text { error). } \\
\text { Main product yield avg.: 92.4\% } \\
\text { Unencapsulated material yield avg.: } 5.5 \%\end{array}$ \\
\hline LDPE (22 MI) & BNL soil & 1 & $37 \mathrm{sec}$ & $\begin{array}{l}\text { Product density: } 1.17 \mathrm{~g} / \mathrm{cm}^{3} \text { (1.08\% error). } \\
\text { Main product yield: } 96.2 \% \\
\text { Unencapsulated material yield avg.: } 3.0 \%\end{array}$ \\
\hline LDPE (50 MI) & BNL soil & 1 & $37 \mathrm{sec}$ & $\begin{array}{l}\text { Product density: } 1.15 \mathrm{~g} / \mathrm{cm}^{3} \text { (1.86\% error). } \\
\text { Main product yield: } 91.9 \% \\
\text { Unencapsulated material yield avg.: } 7.9 \%\end{array}$ \\
\hline
\end{tabular}

${ }^{a}$ dried aqueous salt concentrate based on RFETS characterization data

\subsubsection{Comparison of extrusion and kinetic mixing product density}

Measurements were conducted to compare the densities of 22 and 50 melt index low-density polyethylene processed by kinetic mixing and by extrusion. The polyethylenes were processed alone without any waste surrogate. Table 3.5 shows a comparison between the manufacturer reported 
crystalline density and the measured as-received pellet, extruder product, and kinetic mixer product densities. The densities were calculated by weighing product samples and using a Quantachrome Multipycnometer to measure their volumes. The reported values are an average of three density samples with three replicate measurements for each. The measured densities of processed polyethylene are seen to be less than the crystalline and as-received pellet densities. Differences in the extruder product densities, compared with the measured as-received pellet densities for the 22 and $50 \mathrm{MI}$ LDPE ( 0.5 and $0.8 \%$ respectively), are relatively insignificant. On the other hand, the kinetic mixer product densities are 17.8 and $11.7 \%$ less than the measured as-received pellet densities.

The reason for the large decrease in the mixer product densities is probably due to the robust mechanical action of the mixer which may whip the molten polymer and entrain small amounts of air. Post-processing of the mixer product, e.g., compression molding, would improve the product density.

Table 3.5 Comparison of extrusion and kinetic mixing polyethylene product densities.

\begin{tabular}{|l|c|c|}
\hline \multicolumn{1}{|c|}{ Sample } & LDPE (22 MI) & LDPE (50 MI) \\
\hline \hline crystalline & 0.918 & 0.924 \\
\hline as-received pellets & 0.912 & 0.916 \\
\hline $\begin{array}{l}\text { extruder product } \\
\text { kinetic mixer } \\
\text { product }\end{array}$ & 0.907 & 0.909 \\
\hline
\end{tabular}

${ }^{a}$ Chevron PE 1008.5 ${ }^{b}$ Chevron PE 1409

\subsection{Moisture Removal Capacity}

The ability to process wastes containing elevated levels of moisture increases the applicability of this technology for waste treatment and may eliminate the need for costly thermal pretreatment of the waste as required by extrusion. The test plan to determine the moisture removal capacity specified consecutive process testing at gradually increasing waste moisture content levels. Testing was performed with low-density polyethylene ( $22 \mathrm{MI})$, two waste surrogates and varying batch sizes. Once the maximum process limit was exceeded, the moisture level was decreased by 5 percent and processing was attempted again. A summary of moisture removal capacity experiments for the RFETS salt surrogate is shown in Table 3.6. Testing with the RFETS salt concentrate was performed with an initial batch size of $2 \mathrm{~kg}$. At $10 \%$ moisture, processing was unsuccessful because of feed difficulties. The salts caked together and bridged the mixer feed screw. This feeding difficulty occurred even following the feed tube modification (installation of a Neoprene feed tube as a replacement for the original steel tube), but was alleviated at higher moisture contents of $\geq 20 \mathrm{wt} \%$. At $20 \%$ moisture, batch sizes of 1,2 and $3 \mathrm{~kg}$ were processed. The largest batch size had the shortest cycle time but the most leakage. The one kilogram batch size was selected as optimal to minimize leakage. The broad range of cycle times seen in test sequences at $20 \%$ moisture is likely due to material remaining in the mixing chamber following a particular batch. Any material that remains in the mixing chamber is usually molten polymer adhering to the mixing chamber walls. Subsequent 
batches then have added mass and possible warm polymer to aid frictional heat generation.

For the RFETS salt concentrate, the upper processing limit was exceeded at $40 \mathrm{wt} \%$ waste surrogate moisture content. Processing was acceptable at 25, 30 and $35 \mathrm{wt} \%$ moisture although some leakage of liquid was observed around the discharge gate seal during each batch. The discharge gate is a pneumatically hinged steel door with a tapered edge that provides an interference fit with the mixing chamber wall. These results indicate that the kinetic mixer design has the ability to remove moisture from wet feed materials. However, an improved gate seal to prevent leakage of liquid from the mixing chamber would provide improved performance. As anticipated, leakage was observed to increase with larger batch sizes and greater moisture contents. The product density for processed batches containing LDPE (22 MI), 50 weight percent salt concentrate and no moisture was 1.15 $\mathrm{g} / \mathrm{cm}^{3}$. As seen in Table 3.6, the product density is less for batches from which liquid leaked while processing since dissolved solids were carried along with the leaked water.

A second series of moisture removal experiments were conducted using LDPE (22 MI) and the BNL soil surrogate at a loading of $50 \mathrm{wt} \%$. A summary of these processing results is shown in Table 3.7. The upper processing limit was exceeded at $40 \%$ waste surrogate moisture content. At $\leq 35 \mathrm{wt} \%$ moisture, processing was successful. This is comparable with results for the RFETS salt concentrate. Processing increasing moisture contents with the kinetic mixer has an affect on overall batch processibility. As seen in Table 3.7, the extent of homogeneous mixing (which is inversely proportional to variability in product densities and is measured by the percent error in density data) generally decreases with increasing moisture content. In addition, the batch cycle times increase with increased moisture contents. The proper cycle time also becomes more difficult to identify because the flux point is not easily discernable through noticeable amperage increases or vibrations. Off gas collection efficiency, defined as the ratio of the quantity of moisture collected in the condensate collection vessel to the total moisture contained in the waste, was measured during this series of tests and is also reported in Table 3.7. These data were averaged over all runs in a given series. The relatively low efficiencies (38-50\%) can be attributed to loss of liquid leaking from the process vessel and vapors escaping the process vessel from poor sealing surfaces (e.g., inlet pinch gate and discharge door seals). Modifications to the process vessel design discussed previously as well as improvements in the design of the off gas venting system should significantly improve the collection efficiency. 
Table 3.6 Summary of moisture removal experiments with LDPE (22 MI) and 50 wt $\%$ salt surrogate.

\begin{tabular}{|c|c|c|c|}
\hline $\begin{array}{c}\text { Moisture Content } \\
\text { of Surrogate } \\
\end{array}$ & $\begin{array}{c}\text { Batch Size } \\
(\mathbf{k g})\end{array}$ & Cycle Time & Results \\
\hline dry $(0.26 \%)$ & 2 & $18 \mathrm{sec}$ & $\begin{array}{l}\text { Processed well. } \\
\text { Product density } 1.15 \mathrm{~g} / \mathrm{cm}^{3}(0.65 \% \text { error })\end{array}$ \\
\hline 10 & 2 & $\mathrm{n} / \mathrm{a}$ & $\begin{array}{l}\text { Salts clogged feed throat even with new Neoprene feed } \\
\text { tube. }\end{array}$ \\
\hline 20 & 2 & $\begin{array}{l}3 \min 45 \mathrm{sec} \\
\text { to } \\
8 \min 45 \mathrm{sec}\end{array}$ & $\begin{array}{l}\text { Long cycle times. Liquid leakage around discharge gate. } \\
\text { Poor repeatability as seen in product densities in which } \\
\text { two separate product samples were compared. } \\
\text { Product density batch } 1: 1.15 \mathrm{~g} / \mathrm{cm}^{3}(0.73 \% \text { error) } \\
\text { Product density batch } 2: 1.21 \mathrm{~g} / \mathrm{cm}^{3} 3(1.97 \% \text { error) }\end{array}$ \\
\hline 20 & 3 & $2 \mathrm{~min}$ & $\begin{array}{l}\text { Shorter cycle times with larger batch but significant } \\
\text { leakage as seen in low product density. } \\
\text { Product density } 1.00 \mathrm{~g} / \mathrm{cm}^{3}(0.91 \% \text { error })\end{array}$ \\
\hline 20 & 1 & $\begin{array}{l}3 \mathrm{~min} 20 \mathrm{sec} \\
\text { to } \\
9 \mathrm{~min} 19 \mathrm{sec}\end{array}$ & $\begin{array}{l}\text { Processed well but long cycle times likely caused by } \\
\text { partially blocked off gas vent ports. No leakage. } \\
\text { Product density } 1.16 \mathrm{~g} / \mathrm{cm}^{3}(2.84 \% \text { error }) \text {. }\end{array}$ \\
\hline 25 & 1 & $4 \min 15 \mathrm{sec}$ & $\begin{array}{l}\text { Small amount of leakage but reduced with subsequent } \\
\text { replicate batches. Otherwise, processed well. } \\
\text { Product density } 1.14 \mathrm{~g} / \mathrm{cm}^{3}(5.35 \% \text { error })\end{array}$ \\
\hline 30 & 1 & $5 \min 50 \mathrm{sec}$ & $\begin{array}{l}\text { Cycle time difficult to control. } \\
52 \% \text { off gas collection efficiency. } \\
\text { Product density } 1.13 \mathrm{~g} / \mathrm{cm}^{3}(4.25 \% \text { error })\end{array}$ \\
\hline 40 & 1 & $5 \mathrm{~min} 30 \mathrm{sec}$ & $\begin{array}{l}\text { Significant leakage. Unsuccessful. Product densities } \\
\text { from two batches show low densities due to leakage. } \\
\text { Product density batch 1: } 0.85 \mathrm{~g} / \mathrm{cm}^{3} \text { ( } 4.69 \% \text { error) } \\
\text { Product density batch } 2: 0.89 \mathrm{~g} / \mathrm{cm}^{3} 3.96 \% \text { error) }\end{array}$ \\
\hline 35 & 1 & $5 \mathrm{~min} 55 \mathrm{sec}$ & $\begin{array}{l}\text { Processed acceptably. Small amount of leakage resulting } \\
\text { in lower product density. } \\
52 \% \text { off gas collection efficiency. } \\
\text { Product density } 1.03 \mathrm{~g} / \mathrm{cm}^{3}(3.79 \% \text { error })\end{array}$ \\
\hline
\end{tabular}


Table 3.7 Summary of moistu re removal experiments with LDPE (22 MI) and 50 wt \% BNL soil surrogate.

\begin{tabular}{|c|c|c|c|}
\hline $\begin{array}{c}\text { Moisture Content } \\
\text { of Surrogate } \\
\end{array}$ & $\begin{array}{c}\text { Batch Size } \\
(\mathbf{k g})\end{array}$ & Cycle Time & Results \\
\hline dry $(0.12 \%)$ & 1 & $37 \mathrm{sec}$ & $\begin{array}{l}\text { Processed well. } \\
\text { Unencapsulated material yield avg. } 3 \% \\
\text { Product density } 1.17 \mathrm{~g} / \mathrm{cm}^{3}(1.08 \% \text { error })\end{array}$ \\
\hline 10 & 1 & $53 \mathrm{sec}$ & $\begin{array}{l}\text { Processed well. } \\
\text { Unencapsulated material yield avg. } 1.33 \% \\
38 \% \text { off gas collection efficiency. } \\
\text { Product density } 1.22 \mathrm{~g} / \mathrm{cm}^{3}(3.74 \% \text { error })\end{array}$ \\
\hline 20 & 1 & $1 \mathrm{~min} 30 \mathrm{sec}$ & $\begin{array}{l}\text { Processed acceptably but cycle times were erratic. } \\
\text { Unencapsulated material yield avg. } 7.63 \% \\
46 \% \text { off gas collection efficiency. } \\
\left.\text { Product density } 1.22 \mathrm{~g} / \mathrm{cm}^{3} \text { ( } 3.36 \% \text { error }\right)\end{array}$ \\
\hline 30 & 1 & $4 \mathrm{~min} 15 \mathrm{sec}$ & $\begin{array}{l}\text { Processed acceptably. } \\
\text { Unencapsulated material yield avg. } 2.1 \% \\
50 \% \text { off gas collection efficiency. } \\
\text { Product density } 1.25 \mathrm{~g} / \mathrm{cm}^{3}(5.51 \% \text { error })\end{array}$ \\
\hline 40 & 1 & $\begin{array}{l}4 \mathrm{~min} 30 \mathrm{sec} \\
\text { to } 9 \min 56 \\
\mathrm{sec}\end{array}$ & $\begin{array}{l}\text { Processing unsuccessful. Densities measured of } \\
\text { random samples from two batches. } \\
\text { Product density batch } 1: 1.05 \mathrm{~g} / \mathrm{cm}^{3}(0.57 \% \text { error }) \\
\text { Product density batch } 2: 1.18 \mathrm{~g} / \mathrm{cm}^{3}(0.86 \% \text { error })\end{array}$ \\
\hline 35 & 1 & $6 \mathrm{~min} 27 \mathrm{sec}$ & $\begin{array}{l}\text { Processed acceptably. } \\
\text { Unencapsulated material yield avg. } 6.0 \% \\
48 \% \text { off gas collection efficiency. } \\
\text { Product density } 1.23 \mathrm{~g} / \mathrm{cm}^{3}(6.20 \% \text { error })\end{array}$ \\
\hline
\end{tabular}

A primary drawback to successful processing with elevated moisture levels was leakage of liquids around the discharge gate seal while processing. Leakage occurred because kinetic mixers are not designed for holding "free" liquids. During waste processing, any liquid leakage carries some waste solids and reduces encapsulation efficiency and effectiveness. Methods to eliminate leakage include remanufacturing the discharge gate for tighter tolerances or installing a compressible sealing material such as a gasket in the mating surface between the mixing chamber wall and the discharge gate door. The gasket may be difficult to implement due to the high forces incurred during closure of the discharge gate. Remanufacturing the sealing surfaces is a viable option but was beyond the scope of this effort.

In order to control leakage, superabsorbent (SA) polymers were investigated as additives to temporarily bind "free" water during processing until volatilization temperatures were reached. Two different types of superabsorbent polymers were tested including a starch-based polymer and 
polyacrylate. Testing was performed with LDPE (22 MI) and the RFETS salt surrogate. Results with up to $4 \mathrm{wt} \% \mathrm{SA}$ polymer additive (of the total moisture contained in a batch) indicated that leakage could be prevented but overall processibility was affected. SA polymers can sorb a few hundred percent their weight in water. In this case, the SA polymers as a few percent additive sorbed all "free" water to prevent leakage but cycle times increased significantly, making their use prohibitive.

\subsection{Particle Size Analysis}

A second objective in developing kinetic mixing for polyethylene microencapsulation was to determine the ability of the kinetic mixer to process wastes containing a broader particle size distribution than with extrusion. Minimizing the need for waste pretreatment by size reduction prior to polyethylene microencapsulation would simplify processing and reduce processing costs. For extrusion, the acceptable particle size distribution for wastes is approximately 50 to $2000 \mu \mathrm{m}$. Smaller particles can not be processed due to particle surface wetting limitations with the viscous polymer. Larger particles may be processed by extrusion, up to the screw flight to barrel wall clearance, but extruders are not designed for particle size reduction. Larger particles will also have an adverse impact on waste form leachability.

To determine the particle size processing capabilities of the kinetic mixer, testing was performed using LDPE (22MI), a $2 \mathrm{~kg}$ batch size, and $50 \mathrm{wt} \%$ of either cornstarch or concrete debris as waste surrogates. Consumer-grade cornstarch was used for fine particle processing. The particle size of the cornstarch was reported as "no less than $99 \%$ passing through a 200 mesh $(74 \mu \mathrm{m})$ sieve." Five replicate batches with cornstarch were processed with an average cycle time of 57.9 seconds. The main product yield averaged $85.6 \%$ and the unencapsulated material yield was $2.2 \%$. Overall, the kinetic mixer appeared capable of processing this surrogate. However, due to the fine particle size, the cornstarch was dispersive and airborne powder was observed during feeding and leaked through the discharge gate seal while processing. The $2.2 \%$ unencapsulated material yield was based only on the unencapsulated material collected. The quantity of cornstarch dispersed can not be quantified although the low main product yield of $85.6 \%$ indicates that not all the cornstarch was encapsulated. An improved discharge gate seal would improve processibility of waste surrogates with fine particle sizes by increasing encapsulation efficiency.

Large particle size processing was performed using concrete debris as a surrogate. The concrete debris was prepared as Portland Type I cement then size reduced and classified into four particle size ranges including $>1.75 \mathrm{~mm},>4.75 \mathrm{~mm},>9.5 \mathrm{~mm}$ and $>19 \mathrm{~mm}$. A photograph of the concrete debris in shown in Figure 3.1. Table 3.8 summarizes processing results with the concrete debris. All particles up to $19 \mathrm{~mm}$ fed and processed well. The first three batches up to $19 \mathrm{~mm}$ showed similar results with the product being visually well mixed. The appearance of the product was consistent regardless of the particle size of the feed material. The kinetic mixer was able to break up the concrete rubble and homogeneously mix the concrete particles with the molten polymer. The concrete debris $>19 \mathrm{~mm}$ was too large to fit between flights on the feed screw and consequently would not be conveyed into the mixing chamber. Gradual attrition of the $>19 \mathrm{~mm}$ debris on the screw flights broke up the larger pieces which then fed into the mixing chamber. However, by this 
point the polymer had already been fed and fluxed. This accounts for the lower product density from this batch. The design of the kinetic mixer permits different screw flight configurations on the feed screw. A greater distance between screw flights would permit processing with larger particles sizes than those tested. The feed screw was the limiting factor in determining the maximum particle size noting that the robust mixing action easily size reduced all particles within the mixing chamber to produce visually indistinguishable product. Alternatively, a gravity or crammer feed system would allow introduction of larger particles into the mixing chamber.

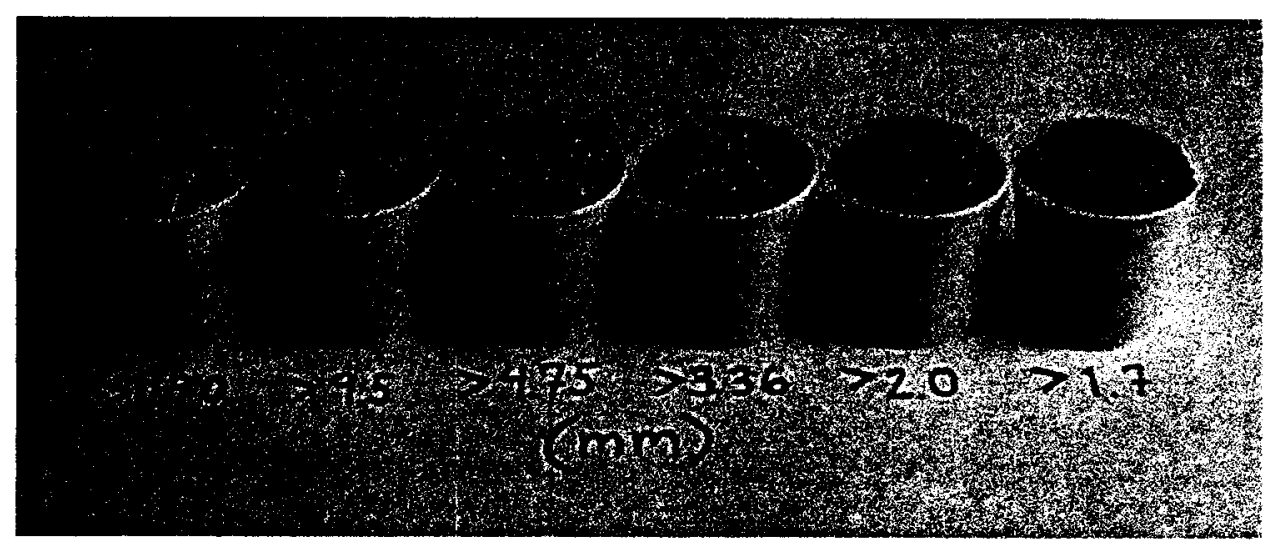

Figure 3.1 Photograph of concrete debris used during large particle size process testing. 
Table 3.8 Processing summary for large particle size testing with LDPE (22 MI), $2 \mathrm{~kg}$ batch size and $50 \mathrm{wt} \%$ concrete debris.

\begin{tabular}{|c|c|l|}
\hline Particle Size & Cycle Time & \multicolumn{1}{c|}{ Results } \\
\hline $1.75-4.75 \mathrm{~mm}$ & $36 \mathrm{sec}$ & $\begin{array}{l}\text { Processed well. } \\
\text { Unencapsulated material yield: } 1.6 \% \\
\text { Main product yield: } 90.0 \% \\
\text { Product density } 1.29 \mathrm{~g} / \mathrm{cm}^{3}(0.45 \% \text { error })\end{array}$ \\
\hline $4.75-9.5 \mathrm{~mm}$ & $41 \mathrm{sec}$ & $\begin{array}{l}\text { Processed well. } \\
\text { Unencapsulated material yield: } 1.2 \% \\
\text { Main product yield: } 87.7 \% \\
\text { Product density } 1.26 \mathrm{~g} / \mathrm{cm}^{3}(0.43 \% \text { error })\end{array}$ \\
\hline $9.5-19 \mathrm{~mm}$ & $40 \mathrm{sec}$ & $\begin{array}{l}\text { Processed well. } \\
\text { Unencapsulated material yield: } 3.0 \% \\
\text { Main product yield: } 88.5 \% \\
\text { Product density } 1.25 \mathrm{~g} / \mathrm{cm}^{3}(1.26 \% \text { error })\end{array}$ \\
\hline$>19 \mathrm{~mm}$ & $57 \mathrm{sec}$ & $\begin{array}{l}\text { Particle size too large to fit in feed screw flights. } \\
\text { Polymer fed and fluxed without most of the debris. } \\
\text { Main product yield: } 64.6 \% \\
\text { Product density } 1.02 \mathrm{~g} / \mathrm{cm}^{3}(0.64 \% \text { error })\end{array}$ \\
\hline
\end{tabular}

\subsection{Recycled Plastic Processing}

Recycled plastics were incorporated into development testing of the kinetic mixer under select conditions to potentially enhance processing and to determine the impact of recycled plastics on waste processibility and waste form performance. The impact of recycled plastics was studied through a series of feasibility tests co-funded by the New York State Office of Recycling Market Development. A separate report on the use of recycled plastics for waste encapsulation was issued [17] and key findings are summarized here.

Feasibility tests to determine processibility of recycled plastics were conducted using both the BNL soil surrogate and RFETS salt surrogate at a loading of 50 weight percent and $2 \mathrm{~kg}$ batch size. For all testing, the surrogates were dry with no added moisture. Each test sequence consisted of five to ten replicate batches. The recycled plastics tested consisted of post-consumer and postindustrial low-density polyethylene, linear low-density polyethylene (LLDPE), high-density polyethylene (HDPE) and polypropylene (PP). A summary of the recycled plastics investigated is shown in Table 3.9. The recycled plastics were used as a direct substitute for virgin resin or were blended with virgin resin at selected ratios based on expected processing characteristics. Samples were fabricated from the kinetic mixer product including grab samples, compressive strength samples and leach testing samples. Grab samples were used to measure product density, homogeneity and consistency for multiple batches processed with the same test conditions. Waste form performance 
was evaluated using compressive strength samples and leach testing samples. Process testing results for each recycled plastic are summarized below.

Table 3.9 Summary of recycled plastics investigated for microencapsulation

\begin{tabular}{||l|l|l|l||}
\hline Plastic & Quantity & Description & Source \\
\hline LDPE (JAM) & $400 \mathrm{lbs}$ & $\begin{array}{l}\text { Industrial recycle. Flake. Melt } \\
\text { index approx. 20. }\end{array}$ & $\begin{array}{l}\text { JAM } \\
\text { Buffalo, NY }\end{array}$ \\
\hline $\begin{array}{l}\text { HDPE (Clearzon } \\
\text { IM8) }\end{array}$ & $300 \mathrm{lbs}$ & $\begin{array}{l}\text { Pelletized blend of post-consumer } \\
\text { packaging materials. Melt index } \\
\text { approx. 6-8. }\end{array}$ & $\begin{array}{l}\text { Clearvue Polymers Inc. } \\
\text { Amsterdam, NY }\end{array}$ \\
\hline HDPE (Clearzon CP) & $300 \mathrm{lbs}$ & $\begin{array}{l}\text { Pelletized post-consumer } \\
\text { detergent and cleaner bottles. } \\
\text { Melt index approx. 0.55. }\end{array}$ & $\begin{array}{l}\text { Clearvue Polymers Inc. } \\
\text { Amsterdam, NY }\end{array}$ \\
\hline LLDPE & $300 \mathrm{lbs}$ & Pelletized post-industrial. & $\begin{array}{l}\text { Resources Plastics } \\
\text { Branford, Ontario }\end{array}$ \\
\hline HDPE & $300 \mathrm{lbs}$ & $\begin{array}{l}\text { Recycled from wire chopping } \\
\text { operation. }\end{array}$ & $\begin{array}{l}\text { Forrester Environmental } \\
\text { Services Inc. } \\
\text { Hampton, NH }\end{array}$ \\
\hline PP/HDPE & $1100 \mathrm{lbs}$ & $\begin{array}{l}\text { Post-consumer beverage bottle } \\
\text { reclaim after segregation of PET }\end{array}$ & $\begin{array}{l}\text { Puretec } \\
\text { Farmingdale, NY }\end{array}$ \\
\hline
\end{tabular}

\section{Recycle LDPE (JAM Plastics)}

This plastic consisted of white flakes with an apparent melt index of 20 , as indicated by the supplier. The commercial or industrial source of this polymer was not known. Based on the plastic type and melt index, this recycled plastic would likely provide good results for waste encapsulation even though it was not possible to confirm the melt index through measurement with a CSI Melt Indexer in accordance with ASTM D-1238. Testing conditions for this recycle are summarized in Table 3.10 .

Processing with this recycled plastic was successful whether used as a direct substitute or in 60 or $80 \%$ proportion with virgin LDPE (V-LDPE). Product appearance in replicate batches and cycle times were consistent and repeatable. The error in grab sample density measurements between replicate batches was also consistent except for a high of $6.08 \%$ for $80 \%$ recycled LDPE (R-LDPE) with the BNL soil surrogate. Since processing at this and all other conditions was observed to be acceptable, the higher percent error is not deemed significant. The average cycle times were longer for the batches containing BNL soil as the waste surrogate because the total batch size during these tests was only $1 \mathrm{~kg}$. This was the only exception to using a $2 \mathrm{~kg}$ batch size during feasibility testing. Smaller batch sizes tend to have longer cycle times due to the smaller total mass and lower friction 
from particle to particle contact. Overall, this polymer works well alone as an encapsulant or combined with virgin polyethylene.

Table 3.10 Testing conditions and product density results for R-LDPE (JAM Plastics).

\begin{tabular}{||l|l|c|l||}
\hline Polymer Type & Waste Surrogate $^{\mathrm{a}}$ & Cycle Time $^{\mathrm{b}}$ & \multicolumn{1}{|c|}{ Results $^{\mathrm{b}}$} \\
\hline \hline $100 \%$ R-LDPE & BNL soil & $1 \mathrm{~min} 29 \mathrm{sec}$ & $\begin{array}{l}\text { Sample density: } 1.16 \mathrm{~g} / \mathrm{cm}^{3} \\
\text { Error: } 2.01 \%\end{array}$ \\
\hline $\begin{array}{l}80 \% \text { R-LDPE } \\
20 \% \text { V-LDPE }\end{array}$ & BNL soil & $1 \mathrm{~min} 38 \mathrm{sec}$ & $\begin{array}{l}\text { Sample density: } 1.05 \mathrm{~g} / \mathrm{cm}^{3} \\
\text { Error: } 6.08 \%\end{array}$ \\
\hline $\begin{array}{l}60 \% \text { R-LDPE } \\
40 \% \text { V-LDPE }\end{array}$ & BNL soil & $1 \mathrm{~min} 38 \mathrm{sec}$ & $\begin{array}{l}\text { Sample density: } 1.10 \mathrm{~g} / \mathrm{cm}^{3} \\
\text { Error: } 3.81 \%\end{array}$ \\
\hline $100 \%$ R-LDPE & RFP surrogate & $59 \mathrm{sec}$ & $\begin{array}{l}\text { Sample density: } 1.04 \mathrm{~g} / \mathrm{cm}^{3} \\
\text { Error: } 3.67 \%\end{array}$ \\
\hline $\begin{array}{l}80 \% \text { R-LDPE } \\
20 \% \text { V-LDPE }\end{array}$ & RFP surrogate & $49 \mathrm{sec}$ & $\begin{array}{l}\text { Sample density: } 1.10 \mathrm{~g} / \mathrm{cm}^{3} \\
\text { Error: } 3.81 \%\end{array}$ \\
\hline $\begin{array}{l}60 \% \text { R-LDPE } \\
40 \% \text { V-LDPE }\end{array}$ & RFP surrogate & $44 \mathrm{sec}$ & $\begin{array}{l}\text { Sample density: } 1.07 \mathrm{~g} / \mathrm{cm}^{3} \\
\text { Error: } 4.65 \%\end{array}$ \\
\hline
\end{tabular}

a 50 weight percent loading. ${ }^{b}$ Based on 5 replicates. ${ }^{c} 22 \mathrm{MI}$ virgin LDPE. ${ }^{d} 50 \mathrm{MI}$ virgin resin.

\section{Recycled HDPE (Clearzon IM8, Clearvue Polymers)}

This recycled plastic was a black, reprocessed and pelletized blend of packaging materials. The melt index given by the supplier was 6-8 g/10 min which was verified experimentally. Process testing was conducted using both the BNL soil and RFETS salt surrogates. Recycled HDPE was blended with virgin LDPE at 60,80 and 100\% for the soil and 20, 40 and $60 \%$ for the RFP surrogate. Virgin polyethylene with melt indices of 22 and $50 \mathrm{~g} / 10 \mathrm{~min}$ were used for feasibility testing with BNL soil and RFP surrogate, respectively. The virgin polyethylene was changed to a higher melt flow in an attempt to partially compensate for the low melt flow of most of the recycled plastics tested.

The testing conditions and product density results for recycied HDPE (Clearzon IM8) are shown in Table 3.11. For each waste surrogate, the grab sample densities were repeatable and consistent and the low percent error indicated excellent batch-to-batch consistency and product homogeneity. For the batch using a $100 \%$ substitution of this recycled polymer for virgin polyethylene with BNL soil, the batch-to-batch consistency was poor. In all cases, the processibility was acceptable except for the $100 \%$ recycled HDPE batch with soil for which noticeable amounts of soil were dispersed while processing or were present on the product surface upon cycle completion and product discharge. Qualitatively, this was observed with the other compositions as well but not as significantly. In summary, based on processing results this recycled plastic can be used for waste encapsulation when added as part of a mixture with virgin LDPE in less than $60-80 \%$ proportion. 
Table 3.11 Testing conditions and product density results for R-HDPE (Clearzon IM8).

\begin{tabular}{|c|c|c|c|}
\hline Polymer Type & Waste Surrogate & Cycle Time $^{\mathrm{b}}$ & Results $^{\mathrm{b}}$ \\
\hline $100 \%$ R-HDPE & BNL soil & $46 \mathrm{sec}$ & $\begin{array}{l}\text { Sample density: } 1.22 \\
\mathrm{~g} / \mathrm{cm}^{3} \\
\text { Error: } 8.95 \%\end{array}$ \\
\hline $\begin{array}{l}80 \% \text { R-HDPE } \\
20 \% \text { V-LDPE }\end{array}$ & BNL soil & $40 \mathrm{sec}$ & $\begin{array}{l}\text { Sample density: } 1.22 \\
\mathrm{~g} / \mathrm{cm}^{3} \\
\text { Error: } 0.15 \%\end{array}$ \\
\hline $\begin{array}{l}60 \% \text { R-HDPE } \\
40 \% \text { V-LDPE }\end{array}$ & BNL soil & $41 \mathrm{sec}$ & $\begin{array}{l}\text { Sample density: } 1.20 \\
\mathrm{~g} / \mathrm{cm}^{3} \\
\text { Error: } 1.50 \%\end{array}$ \\
\hline $\begin{array}{l}60 \% \text { R-HDPE } \\
40 \% \text { V-LDPE }\end{array}$ & RFP surrogate & $50 \mathrm{sec}$ & $\begin{array}{l}\text { Sample density: } 1.16 \\
\mathrm{~g} / \mathrm{cm}^{3} \\
\text { Error: } 1.27 \%\end{array}$ \\
\hline $\begin{array}{l}40 \% \text { R-HDPE } \\
60 \% \text { V-LDPE }\end{array}$ & RFP surrogate & $58 \mathrm{sec}$ & $\begin{array}{l}\text { Sample density: } 1.15 \\
\mathrm{~g} / \mathrm{cm}^{3} \\
\text { Error: } 1.51 \%\end{array}$ \\
\hline $\begin{array}{l}20 \% \text { R-LDPE } \\
80 \% \text { V-LDPE }\end{array}$ & RFP surrogate & $33 \mathrm{sec}$ & $\begin{array}{l}\text { Sample density: } 1.18 \\
\mathrm{~g} / \mathrm{cm}^{3} \\
\text { Error: } 1.08 \%\end{array}$ \\
\hline
\end{tabular}

50 weight percent loading.

${ }^{b}$ Based on 5 replicates

' 22MI virgin LDPE

d $50 \mathrm{MI}$ virgin $\mathrm{LDPE}$

\section{Recycle HDPE (Forrester Environmental Services)}

This recycled plastic was a finely shredded, multi-colored mixture of high-density polyethylene generated during wire chopping operations. The melt index was not measured nor provided by the supplier. Feasibility testing was limited to two compositions consisting of 20 and $40 \%$ recycled material with 50MI virgin LDPE and the RFP surrogate. Waste surrogate processing in the kinetic mixer with this source material was successful. The testing conditions and product density results for recycled HDPE (Forrester) are shown in Table 3.12. The grab sample densities were repeatable and consistent and the low percent error indicated excellent batch-to-batch consistency for the $20 \%$ composition and good batch-to-batch consistency for the $40 \%$ composition. The average cycle time was considerably less for the batches containing $40 \%$ recycle. Just prior to this feasibility test, the mixing blades in the kinetic mixer were repaired because the blade length had decreased substantially from wear.. The blades were built up with weld and hard-faced with Stellite. This resulted in a narrow clearance between the blade tip and the chamber wall resulting in much greater shear. Cycle times noticeably decreased but product homogeneity appeared to remain the same. Overall, from a processing standpoint this recycled plastic worked well and had excellent processibility when added up to a $40 \%$ proportion with virgin LDPE. 
Table 3.12 Testing conditions and product density results for recycled HDPE (Forrester).

\begin{tabular}{|c|c|c|c|}
\hline Polymer Type & Waste Surrogate $^{\mathrm{a}}$ & Cycle Time $^{\mathrm{b}}$ & Results $^{b}$ \\
\hline $\begin{array}{l}20 \% \text { R-HDPE } \\
80 \% \text { V-LDPE }\end{array}$ & RFP surrogate & $36 \mathrm{sec}$ & $\begin{array}{l}\text { Sample density: } 1.14 \\
\text { g/cm }{ }^{3} \\
\text { Error: } 1.44 \%\end{array}$ \\
\hline $\begin{array}{l}40 \% \text { R-HDPE } \\
60 \% \text { V-LDPE }\end{array}$ & RFP surrogate & $12 \mathrm{sec}$ & $\begin{array}{l}\text { Sample density: } 1.21 \\
\mathrm{~g} / \mathrm{cm}^{3} \\
\text { Error: } 2.47 \%\end{array}$ \\
\hline
\end{tabular}

\section{$\underline{\text { Recycled LLDPE (Resource Plastics) }}$}

This recycled plastic was a post-industrial, red and green, pelletized mixture of linear lowdensity polyethylene. The melt index was not provided by the supplier. Feasibility testing was conducted under one set of process conditions which included a polymer blend of $20 \mathrm{wt} \%$ recycled LLDPE and $80 \mathrm{wt} \%$ virgin LDPE (50MI), $50 \mathrm{wt} \%$ loading of RFP surrogate and $2 \mathrm{~kg}$ batch size. Processing was successful with consistent cycle times which averaged 40 seconds over 5 replicates. Product density was $1.15 \mathrm{~g} / \mathrm{cm}^{3}$ with a 0.84 percent error indicating excellent product homogeneity and batch-to-batch consistency. Although not performed within the scope of this effort, higher proportions of this recycle should be readily processible.

\section{Recycled PP/HDPE (Puretec)}

This recycled plastic consisted of a multicolored mixture of $\mathrm{PP}$ (from beverage bottle labels and caps), HDPE (from beverage bottle base cups), and a small fraction ( $<1 \mathrm{wt} \%)$ of poly(ethylene terephthalate) (PET) from post-consumer beverage bottle reclaim. Each of these polymers in addition to the virgin LDPE have a slightly different melting temperature thereby increasing the complexity of processing. In previous testing, when added as a feed stock blend, this material was successful in reducing cycle times for processing wet wastes. For this feasibility test conducted at one set of processing conditions, a blend of $20 \mathrm{wt} \%$ recycled plastic was added to $80 \mathrm{wt} \% 50 \mathrm{MI}$ virgin LDPE in a $2 \mathrm{~kg}$ batch containing $50 \mathrm{wt} \%$ RFP surrogate. Processing was successful with cycle times that averaged 13 seconds based on 5 replicates. The short cycle times were a direct result of the new mixing blades which were repaired just prior to this feasibility test. Cycles were easily controlled because of the short time necessary to melt and mix the materials in the mixer. The product density averaged $1.19 \mathrm{~g} / \mathrm{cm}^{3}$ with a $4.57 \%$ error. Visual observations of the product homogeneity indicated some variation between replicate batches. In summary, this recycled plastic produced acceptable results when processed under formulation parameters tested, i.e., ratio of $20 \mathrm{wt} \%$ recycled plastic blended with $80 \mathrm{wt} \%$ virgin LDPE. Slightly higher quantities of this recycled polymer may also be acceptable. 


\subsection{MIXED WASTE PROCESSING DEMONSTRATION}

Following successful process development using surrogate waste streams, the system was demonstrated using actual mixed wastes. . Prior to "hot" testing, facility modifications were made, as identified in Section 2.3, Kinetic Mixer Modifications and Improvements. This primarily included the construction of a HEPA ventilated enclosure to surround the process equipment. A glove box was mounted above the enclosure to permit manual feeding of waste and binder materials to the mixer. Additionally, a thorough safety plan was prepared and reviewed by the BNL Department of Advanced Technology Safety Committee.[18]

The waste selected for confirmation processing/demonstration was radiologically contaminated BNL soil with concentrations of Cs-137 (300 - 500 pCi/g and Sr-90 (5 -10 pCi/g). This soil is part of the BNL Operable Unit I superfund cleanup program. Chromium in the form of potassium chromate $\left(\mathrm{K}_{2} \mathrm{Cr}_{2} \mathrm{O}_{7}\right)$ was added to the soil at a concentration of $5000 \mathrm{ppm}$. Before processing the radiologically contaminated soil, a go/no-go test was performed with a hazardous waste surrogate consisting of non-radioactive BNL soil spiked with $5000 \mathrm{ppm}$ chromium. A total of five batches of the hazardous waste surrogate were processed at a waste loading of $50 \mathrm{wt} \%$ with and without additives. Product specimens from this testing were leach tested in accordance with EPA Toxicity Characteristic Leaching Procedure (TCLP) protocol [15]. Leach testing results (presented in Section 5.2) were successful thereby permitting advancement to confirmation processing and demonstration with mixed waste soils.

"Hot" demonstration processing was conducted for a total of 15 batches, each containing 1 $\mathrm{kg}$ of contaminated soil. The encapsulated product was formulated into waste form test specimens for performance testing including compressive strength and TCLP. Waste form performance and leach data are presented in the following section, 5.0 Waste Form Characterization. A summary of processing results for "cold" and "hot" BNL soils are shown in Table 4.1. Processing was successful with good repeatability. The only difficulty was encountered while processing the BNL soil surrogate with $2 \mathrm{wt} \%$ sodium sulfide. The additive was in a hydrated form and therefore not thermally stable under polymer processing conditions. The cycle time was longer than without additive and the appropriate cycle time to flux was difficult to discern. The cycle time increased from $11.8 \mathrm{sec}$ for the LDPE (22 MI) and $50 \mathrm{wt} \% \mathrm{BNL}$ soil surrogate mixture to $22.4 \mathrm{sec}$ for the same mixture containing $2 \mathrm{wt} \%$ hydrated additive. These cycle times are not directly comparable to cycle times noted during earlier development testing because, as mentioned in section 2.3, Kinetic Mixer System Modifications and Improvements, the mixing blades were repaired just prior to the BNL soil confirmation processing. The repaired blades resulted in substantially shorter cycle times due to improved shear. No processing difficulties were encountered with the "hot" BNL soil. For these runs, the additive was thermally pretreated to remove waters of hydration. 
Table 4.1 Processing results for kinetic mixer confirmation testing with 50 weight percent non-radioactive and radiologically contaminated BNL soil.

\begin{tabular}{|c|c|c|c|}
\hline Binder & Waste & $\begin{array}{l}\text { Cycle } \\
\text { Time }\end{array}$ & Results \\
\hline LDPE (22 MI) & $\begin{array}{l}\text { non-rad BNL soil } \\
5000 \mathrm{ppm} \mathrm{Cr}\end{array}$ & $11.8 \mathrm{sec}$ & ( 3 batches). Processed well. \\
\hline $\begin{array}{l}\text { LDPE }(22 \mathrm{MI}) \\
2 \mathrm{wt} \% \mathrm{Na}_{2} \mathrm{~S} \text { additive }\end{array}$ & $\begin{array}{l}\text { non-rad BNL soil } \\
5000 \mathrm{ppm} \mathrm{Cr}\end{array}$ & $22.4 \mathrm{sec}$ & $\begin{array}{l}\text { ( } 1 \text { batch). Additive in form of } \mathrm{Na}_{2} \mathrm{~S}-9 \mathrm{H}_{2} \mathrm{O} \text {. Waters } \\
\text { of hydration caused longer cycle times which were } \\
\text { difficult to discern. }\end{array}$ \\
\hline $\begin{array}{l}\text { LDPE ( } 22 \mathrm{MI}) \\
2 \mathrm{wt} \% \text { Cyanex } \\
\text { additive }\end{array}$ & $\begin{array}{l}\text { non-rad BNL soil } \\
5000 \mathrm{ppm} \mathrm{Cr}\end{array}$ & $12.3 \mathrm{sec}$ & (1 batch). Processed well. Dried additive used. \\
\hline $\begin{array}{l}\text { LDPE }(22 \mathrm{MI}) \\
2 \mathrm{wt} \% \mathrm{Na}_{2} \mathrm{~S} \text { additive }\end{array}$ & "hot" BNL soil & $30.0 \mathrm{sec}$ & $\begin{array}{l}\text { ( } 1 \text { batch). Processed well. Dried additive used. } \\
\text { Fabricated compressive strength specimens. }\end{array}$ \\
\hline $\begin{array}{l}\text { LDPE }(22 \mathrm{MI}) \\
2 \mathrm{wt} \% \mathrm{Na}_{2} \mathrm{~S} \text { additive }\end{array}$ & $\begin{array}{l}\text { "hot" BNL soil } \\
5000 \text { ppm Cr }\end{array}$ & $32.4 \mathrm{sec}$ & $\begin{array}{l}\text { ( } 3 \text { batches). Processed well. Dried additive used. } \\
\text { Fabricated TCLP specimens. }\end{array}$ \\
\hline $\begin{array}{l}\text { LDPE }(22 \mathrm{MI}) \\
2 \mathrm{wt} \% \mathrm{Na}_{2} \mathrm{~S} \text { additive }\end{array}$ & $\begin{array}{l}\text { "hot" BNL soil } \\
5000 \text { ppm Cr }\end{array}$ & $37.5 \mathrm{sec}$ & $\begin{array}{l}\text { ( } 3 \text { batches). Processed well. Dried additive used. } \\
\text { Fabricated compressive strength specimens. }\end{array}$ \\
\hline $\begin{array}{l}\text { LDPE }(22 \mathrm{MI}) \\
2 \mathrm{wt} \% \mathrm{Na}_{2} \mathrm{~S} \text { additive }\end{array}$ & $\begin{array}{l}\text { "hot" BNL soil } \\
5000 \mathrm{ppm} \mathrm{Cr}\end{array}$ & $34.1 \mathrm{sec}$ & $\begin{array}{l}\text { ( } 6 \text { batches). Processed well. Dried additive used. } \\
\text { Fabricated compressive strength specimens. }\end{array}$ \\
\hline LDPE (22 MI) & "hot" BNL soil & $23.4 \mathrm{sec}$ & ( 2 batches). Processed well. \\
\hline
\end{tabular}

\subsection{WASTE FROM CHARACTERIZATION}

To establish waste form performance, mechanical integrity testing and leach testing was performed. These factors are important in determining whether a waste form meets minimum criteria for safe disposal and provides long-term containment of the hazardous or radioactive components. Product specimens were not formulated during development testing because development work primarily focused on defining the mixer capabilities with regard to moisture removal and acceptable particle size distribution. However, while recycled plastics processing, product specimens were formulated for performance testing in order to adequately determine the impact of recycled plastics on both processing and waste form integrity. Recycled plastic waste forms were subjected to compressive strength testing and leach testing in accordance with the ASTM C1308, Accelerated Leach Test.[19]

Mixed waste confirmation processing consisted of a go/no-go test with "clean" BNL soil as a surrogate and radiologically contaminated BNL soil. Both the surrogate and the "hot" soil were spiked with $5000 \mathrm{ppm}$ chromium. TCLP leach testing was performed on product specimens from the go/no-go process confirmation ("cold" BNL soil) as well as from "hot" BNL soil tests. Compressive strength testing was performed on product specimens from "hot" BNL soil confirmation processing. 


\subsection{Recycled Plastic Waste Form Performance}

Recycled plastic waste torms containing various polymer combinations with $50 \mathrm{wt} \%$ RFETS salt surrogate were tested for compressive strength in order to quantify their mechanical integrity. Testing was conducted in accordance with ASTM D695, "Standard Test Method for Compressive properties of Rigid Plastics" using an Instron 5582 Materials Tester.[20] Each sample with nominal dimensions of $5.1 \mathrm{~cm}(2 \mathrm{in})$ by $10.2 \mathrm{~cm} \mathrm{(4} \mathrm{in)} \mathrm{was} \mathrm{compressed} \mathrm{uniaxially} \mathrm{at} \mathrm{a} \mathrm{constant} \mathrm{loading} \mathrm{rate}$ of $1.0 \pm 0.5 \mathrm{~mm} / \mathrm{min}$ until sample failure by either plastic deformation or ductile fracture. The results obtained included a plot of stress versus strain, percent deformation and maximum compressive strength. For specimens at a given polymer and waste composition, three replicate samples were tested to verify statistical significance. Although there is no minimum waste form compressive strength required for disposal of DOE hazardous and radioactive wastes, the Nuclear Regulatory Commission recommends a minimum $4.14 \mathrm{MPa}(60 \mathrm{psi})$ for licensable polymer solidification processes.

A summary of the compressive strengths of recycled plastic waste forms is shown in Table 5.1. All samples were above the recommended NRC minimum guideline of $4.14 \mathrm{MPa}(60 \mathrm{psi})$ for compressive strength. The failure mechanism for all samples was ductile fracture with the percent deformation at failure varying from a high of $45-50$ for samples comprised of LDPE to approximately 15-25 for samples containing HDPE.

Recycled plastic waste form leachability was conducted to measure the retention of potential contaminants in recycled plastic final waste forms. Testing was performed in accordance with the Accelerated Leach Test, ASTM C1308, a method developed at BNL for waste form leachability projections. Leach samples were fabricated as $2.5 \mathrm{~cm}(1 \mathrm{in})$ by $2.5 \mathrm{~cm}(1 \mathrm{in})$ right cylinders during processibility testing. Over an 11 day period, the fraction of sodium $(\mathrm{Na})$ leached from the samples was measured and calculated as the incremental or cumulative fraction leached. The initial quantity of sodium was known based on the composition of the RFETS surrogate which was encapsulated in each waste form sample at a 50 weight percent loading. Figure 5.1 shows the cumulative fraction leached of sodium (average of 3 replicates) for three recycle polymer compositions and a run at an elevated temperature of $50^{\circ} \mathrm{C}$ compared with a baseline run of virgin LDPE. All data indicated a diffusion controlled leach mechanic, as is usually the case for polymer waste forms. It can be seen that each curve follows the same trend regardless of the composition. An additional replicate was conducted of the $60 \mathrm{wt} \%$ R-LDPE (JAM), $40 \mathrm{wt} \%$ virgin LDPE at an elevated temperature of $50^{\circ} \mathrm{C}$ in order to accelerate the leach rate. Higher temperatures should accelerate leaching because contaminant solubility is temperature dependent and will increase accordingly. The leach rate was a little higher at the elevated temperature although not significantly. Included in Figure 5.1 are the plus and minus two sigma error bars for the baseline runs with $100 \%$ virgin LDPE. This represents the statistical 95 percent confidence interval for the baseline run. All data, regardless of the composition, is found to fall within this range. The cumulative fraction leached did not exceed 0.08 or $8 \%$ of the initial source term of sodium in the samples over the entire leach test. The lowest leaching was observed with $100 \%$ recycled LDPE (JAM), actually performing better than the virgin LDPE. The mixture of $60 \mathrm{wt} \%$ R-LDPE (JAM) $/ 40 \mathrm{wt} \%$ virgin-LDPE had nearly identical leaching to the baseline of $100 \%$ virgin-LDPE. The greatest leaching was from the elevated temperature run and the batches comprised of $20 \mathrm{wt} \%$ R-HDPE (Clearzon IM8)/80 wt\% virgin-LDPE. Overall, from 
a leaching waste form performance standpoint, all recycled plastics and compositions had acceptable leach rates.

Table 5.1 Compressive strength of recycled plastic waste forms.

\begin{tabular}{|c|c|c|c|}
\hline \multirow[t]{2}{*}{ Sample } & \multicolumn{2}{|c|}{ Max. Compressive Strength } & \multirow{2}{*}{$\begin{array}{l}\text { \% Deformation at } \\
\text { Failure }\end{array}$} \\
\hline & $(\mathbf{M P a})$ & (psi) & \\
\hline 100\% R-LDPE (JAM) & 12.36 & 1793 & 50.0 \\
\hline $\begin{array}{l}80 w t \% \text { R-LDPE (JAM) } \\
20 w t \% \text { V-LDPE }\end{array}$ & 10.29 & 1492 & 49.9 \\
\hline $\begin{array}{l}60 w t \% \text { R-LDPE (JAM) } \\
40 w t \% \text { V-LDPE }\end{array}$ & 8.58 & 1245 & 45.2 \\
\hline $\begin{array}{l}60 \mathrm{wt} \% \text { R-HDPE (Clearzon IM8) } \\
40 \mathrm{wt} \% \text { V-LDPE }\end{array}$ & 15.18 & 2202 & 13.0 \\
\hline $\begin{array}{l}40 \mathrm{wt} \% \text { R-HDPE (Clearzon IM8) } \\
60 \mathrm{wt} \% \text { V-LDPE }\end{array}$ & 13.66 & 1982 & 15.1 \\
\hline $\begin{array}{l}20 w t \% \text { R-HDPE (Clearzon IM8) } \\
80 w t \% \text { V-LDPE }\end{array}$ & 10.44 & 1515 & 15.22 \\
\hline $\begin{array}{l}20 w t \% \text { R-HDPE (Clearzon CP) } \\
80 w t \% \text { V-LDPE }\end{array}$ & 11.43 & 1658 & 15.09 \\
\hline $\begin{array}{l}20 w t \% \text { R-LLDPE (Resource Plastics) } \\
80 w t \% \text { V-LDPE }\end{array}$ & 11.67 & 1691 & 30.0 \\
\hline $\begin{array}{l}40 w t \% \text { R-HDPE (Forrester) } \\
60 w t \% \text { V-LDPE }\end{array}$ & 12.91 & 1873 & 22.1 \\
\hline $\begin{array}{l}20 w t \% \text { R-HDPE (Forrester) } \\
80 w t \% \text { V-LDPE }\end{array}$ & 11.85 & 1718 & 24.9 \\
\hline $\begin{array}{l}20 w t \% \text { R-PP/HDPE (Puretec) } \\
80 w t \% \text { V-LDPE }\end{array}$ & 12.46 & 1807 & 11.7 \\
\hline
\end{tabular}




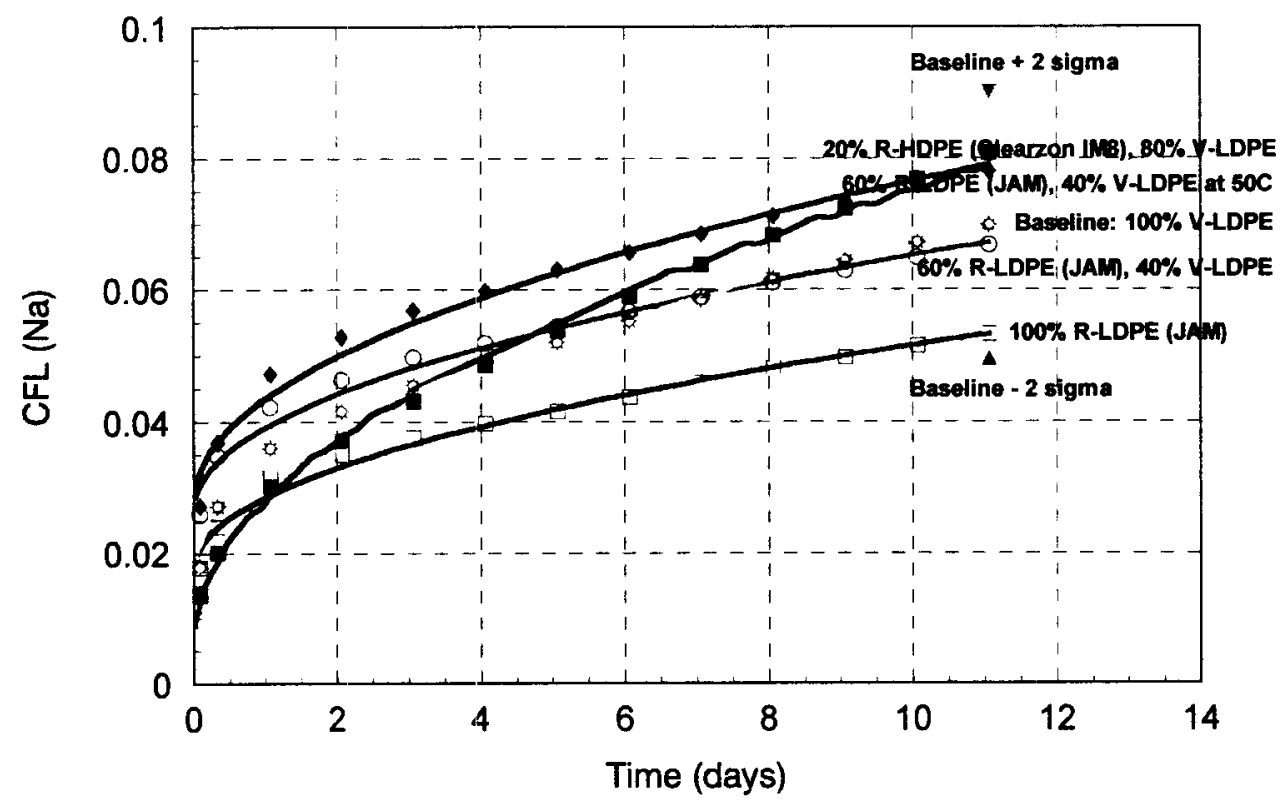

Figure 5.1 ALT leach results for waste forms containing 50 wt\% RFETS salt surrogate.

\subsection{Mixed Waste Encapsulated Product Performance}

Leach testing was performed on polyethylene waste forms containing the BNL soil surrogate for the go/no-go test. Successful results during the go/no-go processing and waste form leach test permitted advancement to confirmation processing with radiologically contaminated BNL soil samples. Product specimens were formulated from the polyethylene encapsulated "hot" BNL soil for leach testing as well as compressive strength testing.

To permit leach testing the BNL soil surrogate and the radiologically contaminated BNL soil, both were spiked with $5000 \mathrm{ppm}$ Cr. Leaching was conducted in accordance with the TCLP test which is an 18 hour extraction of $100 \mathrm{~g}$ of sample in $2000 \mathrm{~g}$ of a buffered leachant (either $\mathrm{pH} 2.88$ or 4.93). The leachant $\mathrm{pH}$ is selected based on a sample pre-test which determines the buffering capacity of the waste or treated waste. Test samples are agitated in an end-over-end fashion at 30 $\pm 2 \mathrm{rpm}$ for the test duration. On completion, the solutions are filtered using 0.6-0.8 micron glass fiber filters. The concentration of $\mathrm{Cr}$ in the filtered leachates was analyzed by Inductively Coupled Plasma (ICP) spectroscopy using a Varian Liberty 100 emission analyzer.

Leach samples were fabricated during processing testing as $6 \mathrm{~mm}$ diameter by $6 \mathrm{~mm}$ high right cylindrical pellets in Teflon molds, as per the $9.5 \mathrm{~mm}$ maximum size requirement. Pellets were used as the leach specimens in order to simulate larger final waste forms. TCLP results for BNL soil samples are shown in Table 5.2. The leach data is seen to be well below the current TCLP limit as well as the more stringent Universal Treatment Standard (UTS) limit for chromium. The untreated soil failed the TCLP test at both standards demonstrating the success of polyethylene encapsulation 
for this material. The leach results may not be entirely indicative of the mixer product since the mixer product typically contains a small fraction of unencapsulated material on the product surface. Posttreatment or handling improves the product appearance. Fabricating the TCLP pellets required additional handling so therefore the pellets had a slightly improved appearance.

Compressive strength testing results for LDPE waste forms containing radiologically contaminated BNL soil are shown in Table 5.3. This testing was also conducted in accordance with ASTM D-695, "Standard Test Method for Compressive properties of Rigid Plastics." Reported are the maximum compressive strengths for 10 replicates as well as the percent deformation at failure. These maximum compressive strengths are consistent with other polyethylene waste forms. All samples ultimately failed by ductile fracture. The maximum compressive strengths easily exceeded the minimum compressive strength of $4.14 \mathrm{MPa}(60 \mathrm{psi})$ required by the Nuclear Regulatory Commission for licensing polymer solidification processes.

Table 5.2 TCLP leach results for LDPE waste forms with $50 \mathrm{wt} \%$ BNL soil spiked with 5000 ppm Chromium

\begin{tabular}{|c|c|c|c|c|}
\hline \multirow[t]{2}{*}{ Polymer } & \multirow[t]{2}{*}{ Waste } & \multicolumn{3}{|c|}{ Cr Concentration (mg/l) } \\
\hline & & Measured & $\begin{array}{l}\text { TCLP } \\
\text { Limit }\end{array}$ & $\begin{array}{l}\text { UTS } \\
\text { Limit }\end{array}$ \\
\hline \multicolumn{5}{|l|}{ go/no-go tests } \\
\hline $\begin{array}{l}\text { Baseline soil } \\
\text { (untreated) }\end{array}$ & $\begin{array}{l}\text { non-rad BNL soil } \\
5000 \mathrm{ppm} \mathrm{Cr}\end{array}$ & 41.34 & 5 & 0.85 \\
\hline LDPE (22 MI) & $\begin{array}{l}\text { non-rad BNL soil } \\
5000 \mathrm{ppm} \mathrm{Cr}\end{array}$ & 0.1505 & 5 & 0.85 \\
\hline $\begin{array}{l}\text { LDPE }(22 \mathrm{MI}) \\
2 \mathrm{wt} \% \mathrm{Na}_{2} \mathrm{~S} \text { additive }\end{array}$ & $\begin{array}{l}\text { non-rad BNL soil } \\
5000 \mathrm{ppm} \mathrm{Cr}\end{array}$ & 0.05163 & 5 & 0.85 \\
\hline $\begin{array}{l}\text { LDPE ( } 22 \mathrm{MI}) \\
2 \text { wt\% Cyanex additive }\end{array}$ & $\begin{array}{l}\text { non-rad BNL soil } \\
5000 \mathrm{ppm} \mathrm{Cr}\end{array}$ & 0.1825 & 5 & 0.85 \\
\hline \multicolumn{5}{|c|}{ mixed waste confirmation processing } \\
\hline $\begin{array}{l}\text { LDPE }(22 \mathrm{MI}) \\
2 \mathrm{wt} \% \mathrm{Na}_{2} \mathrm{~S} \text { additive }\end{array}$ & $\begin{array}{l}\text { "hot" BNL soil } \\
5000 \mathrm{ppm} \mathrm{Cr}\end{array}$ & 0.04294 & 5 & 0.85 \\
\hline
\end{tabular}


Table 5.3 Compressive strengths of LDPE waste forms with $50 \mathrm{wt} \%$ BNL soil

\begin{tabular}{|c|c|c|c||}
\hline \multirow{2}{*}{ Sample } & \multicolumn{2}{|c|}{$\begin{array}{c}\text { Max. Compressive } \\
\text { Strength }\end{array}$} & $\begin{array}{c}\text { \% Deformation at } \\
\text { Failure }\end{array}$ \\
\cline { 2 - 3 } & (MPa) & (psi) & \\
\hline \hline 1 & 16.79 & 2436 & 38.3 \\
\hline 2 & 16.31 & 2364 & 39.8 \\
\hline 3 & 12.04 & 1746 & 29.6 \\
\hline 4 & 14.51 & 2104 & 33.3 \\
\hline 5 & 14.85 & 2154 & 31.2 \\
\hline 6 & 16.20 & 2349 & 34.2 \\
\hline 7 & 18.28 & 2651 & 40.0 \\
\hline 8 & 19.13 & 2775 & 48.2 \\
\hline 9 & 14.41 & 2090 & 31.8 \\
\hline 10 & 16.13 & 2339 & 34.3 \\
\hline Mean & 15.84 & 2301 & 36.1 \\
Std. Dev. & 2.03 & 280 & 5.3 \\
2 o error & 1.46 & 201 & 3.8 \\
\% Error & 9.2 & 8.7 & 10.5 \\
\hline
\end{tabular}




\subsection{SUMMARY AND CONCLUSIONS}

Kinetic mixing was developed as an alternative processing method for polyethylene microencapsulation. Mixer operation was established by studying the effect of varying process parameters such as batch size, polymer type, waste type, and moisture content on cycle time and on the mixer product. The capabilities of the mixer to process wastes with high moisture contents and broad particle size distributions were also defined. Confirmation processing with radiologically contaminated soil demonstrated the viability of kinetic mixing in conjunction with successful waste form leaching and mechanical integrity results.

Conclusions summarizing the effect of process parameters, defining the capabilities of the kinetic mixer and the overall usefulness of kinetic mixing for polyethylene microencapsulation are given below. Recommendations for potential process improvements are also presented.

Impact of variables on processing

- Larger batch sizes decrease cycle time due to improved frictional heat generation through increased shear.

- Increasing waste surrogate moisture content increases batch cycle times due to additional energy required to volatilize moisture prior to melting of polymer.

- Polymer type affects batch cycle time and product. Polymers with lower melt index (higher melt viscosity) require longer cycle times and may adversely impact encapsulation effectiveness since particle "wetting" is more difficult with more viscous melts. Conversely, polymers with high melt index (low melt viscosity) can result in difficulty controlling the melt and an excessively sticky product.

Moisture removal capacity

- Maximum moisture removal capacity for both RFETS salt concentrate and BNL soil surrogate was $35 w t \%$. Significant leakage occurred around the discharge gate seal while processing at higher moisture contents.

- At higher moisture contents, homogeneity of mixing decreased as evidenced by increasing statistical error in replicate batch density measurements.

- Ability to discern appropriate cycle times became more difficult with increasing moisture contents.

Varying particle size processing

- Fine particles $<74 \mu \mathrm{m}$ were processed but low main product yields indicated incomplete encapsulation. Significant dispersion of fine particies was noted while feeding, processing (leakage around discharge gate seal) and upon discharge.

- A maximum particle size of $19 \mathrm{~mm}$ was successfully processed. The maximum particle size is limited by the design of the feed screw, specifically the distance between consecutive screw flights.

- Robust agitation of waste in the mixing chamber prior to fluxing can lead to size reduction of particles. 
Recycled plastics processing

- Design of the kinetic mixer permits changing polymer type with only minor operational changes so that different recycled plastics can be easily substituted.

- Some recycled plastics can be readily used in place of virgin resin based on successful processing and waste form performance results. Specifically, recycled LDPE with a melt index of 20, was comparable to virgin LDPE used for kinetic mixing and produced excellent results. Other recycled plastics worked well when blended with virgin polyethylene.

Demonstration/Confirmation processing

- TCLP leach testing of non-rad BNL soil surrogate spiked with 5000 ppm chromium resulted in reductions in $\mathrm{Cr}$ concentrations of 274 times and 805 times for polyethylene encapsulated samples without and with additive, respectively. In both cases, results were well below both the existing TCLP limit ( $5 \mathrm{ppm} \mathrm{Cr})$ and the more stringent UTS standard $(0.85 \mathrm{ppm} \mathrm{Cr})$ expected to take effect in 1998.

- Radiologically contaminated BNL soil was successfully processed. Waste form testing indicated successful leaching results and excellent mechanical integrity. TCLP concentrations of $\mathrm{Cr}$ were reduced by a factor of 963 times compared with untreated baseline soil, (again well below TCLP and UTS limits). Compression testing resulted in average strengths of 15.84 $\mathrm{MPa}$, well above the NRC guideline of 4.14 MPa.

Processing Observations

- Kinetic mixer design permits processing of wastes with moisture contents up to $35 \mathrm{wt} \%$, greatly exceeding those permissible by extrusion (up to $2 \mathrm{wt} \%$ ).

- Particle size distribution for acceptable processing by kinetic mixing is broader than permissible by extrusion.

- Feed materials can be varied on a batch-to-batch basis since only cycle time will be affected.

- Cycle times are occasionally difficult to control based on amperage changes or vibrations which can be difficult to discern. As a result, some batches were discharged prematurely, resulting in unfluxed materials or insufficiently mixed feed materials. On the other hand, some polymers are temperature sensitive so excessive cycle times cause the polymer to overheat and become sticky, necessitating the manual clean out of the mixing chamber. A temperature sensor measuring melt temperature would help alleviate these problems.

- QA/QC can be more difficult to control for a batch process (e.g., kinetic mixing) than for continuous process (e.g., extrusion).

- Discharged kinetic mixer product can contain unencapsulated material on the surface, necessitating some degree of post treatment or handling.

Recommendations for improved processing

- Improved design for the discharge gate seal to prevent leakage of "free" liquids and dispersion of fines while processing. An improved seal would potentially increase the maximum quantity of moisture that can be processed and enhance encapsulation effectiveness for fine particles.

- Improved feed method to convey materials into the mixing chamber. Difficulties were encountered feeding wet salt surrogates due to bridging. "Free" liquids also leaked from below the feed screw. Eliminating the feed screw by feeding directly to the mixing chamber 
would alleviate these difficulties. Solids and wet solids could be gravity or ram fed via a slide gate. Pumpable sludges and liquids can be injected under pressure by a diaphragm or other suitable pump.

- Installation of an optical temperature sensor would improve appropriate cycle time determination and improve overall consistency and repeatability. 


\section{REFERENCES}

1. Kalb, P.D. and P. Colombo, "Composition and Process for the Encapsulation and Stabilization of Radioactive, Hazardous, and Mixed Wastes," U.S. Patent Nos. 5,649,323, July 15, 1997, and 5,732,364, March 24,1998.

2. Kalb, P.D. and P. Colombo, "Polyethylene Solidification of Low-Level Wastes, Topical Report," BNL-51867, Brookhaven National Laboratory, Upton, NY, October 1984.

3. Heiser, J.H., Franz, E.M. and Colombo, P., "A Process for Solidifying Sodium Nitrate Waste in Polyethylene," Environmental Aspects of Stabilization and Solidification of Hazardous and Radioactive Wastes, ASTM STP 1O33, Cote and Gilliam (editors), American Society for Testing and Materials, Philadelphia, PA, 1989.

4. Franz, E.M., J.H. Heiser, III, and P. Colombo, "Immobilization of Sodium Nitrate Waste With Polymers, Topical Report," BNL-52081, Brookhaven National Laboratory, Upton, NY, April 1987.

5. Kalb, P.D., J.H. Heiser, III, and P. Colombo, " Polyethylene Encapsulation of Nitrate Salt Wastes: Waste Form Stability, Process Scale-up, and Economics," BNL- 52293, Brookhaven National Laboratory, Upton NY, July 1991.

6. Kalb, P.D., and M. Fuhrmann, "Polyethylene Encapsulation of Single-Shell Tank Wastes," BNL-52365, Brookhaven National Laboratory, Upton, NY, September 1992.

7. Kalb, P.D., J.H. Heiser, and P. Colombo, "Long-Term Durability of Polyethylene for Encapsulation of Low-Level Radioactive, Hazardous, and Mixed Wastes," Emerging Technologies in Hazardous Waste Management III, D.W. Tedder and R.G. Pohland, eds., American Chemical Society Symposium Series 518, Washington, D.C., 1993.

8. Kalb, P.D., J.W. Adams, M. Meyer, and H. Holmes Burns, "Thermoplastic Encapsulation Treatability Study for a Mixed Waste Incinerator Off-Gas Scrubbing Solution," Stabilization and Solidification of Hazardous, Radioactive and Mixed Wastes, 3rd Vol., ASTM STP-1240, American Society for Testing and Materials, W. Conshohocken, PA, 1996.

9. Adams, J.W., and P.D. Kalb, "Thermoplastic Stabilization Treatability Study for a Chloride, Sulfate and Nitrate Salts Mixed Waste Surrogate," American Chemical Society, D.W. Tedder and R.G. Pohland, eds., in press.

10. Kalb, P.D., and P.R. Lageraaen, "Polyethylene Encapsulation Full-Scale Technology Demonstration," BNL-52478, Brookhaven National Laboratory, Upton, NY, 1995.

11. Kalb, P.D., and P.R. Lageraaen, "Full-Scale Technology Demonstration of a Polyethylene Encapsulation Process for Radioactive, Hazardous, and Mixed Wastes," Journal of Environmental Science and Health, Vol. A31, No. 7, pp. 1767-1780, 1996. 
12. Lageraaen, P.R., B.R. Patel, P.D. Kalb, and J.W. Adams, "Treatability Studies for Polyethylene Encapsulation of INEL Low-Level mixed Wastes," BNL-62620, Brookhaven National Laboratory, Upton, NY, October 1995.

13. U.S. Nuclear Regulatory Commission, "Licensing Requirements for Land Disposal of Radioactive Waste," 10 CFR 261, US NRC, Washington, DC, May 1983.

14. U.S. Nuclear Regulatory Commission, "Technical Position on Waste Form, Revision 1," Final Waste Classification and Waste From Technical Position Papers, US NRC, Washington, DC, January 1991.

15. U.S. Environmental Protection Agency, "Toxicity Characteristic Leaching Procedure (TCLP)," 40 CFR 261, Appendix II, US EPA, Washington, DC, September 1994.

16. Patel, B.R., P.R. Lageraaen, and P.D. Kalb, "Review of Potential Processing Techniques for the Encapsulation of Wastes in Thermoplastic Polymers," BNL-62200, Brookhaven National Laboratory, Upton, NY, August 1995.

17. Lageraaen, P.R., and P.D. Kalb, "Use of Recycled Polymers for Encapsulation of Radioactive, Hazardous and Mixed Wastes," Brookhaven National Laboratory, Upton NY, in press.

18. Kalb, P.D., et al., "Demonstration of a Kinetic Mixer Project Review Documentation Rev 2.0" Brookhaven National Laboratory, Internal Document, September 1997.

19. ASTM, "Accelerated Leach Test for Diffusive Releases from Solidified Waste and a Computer Program to model Diffusive, Fractional Leaching from Cylindrical Waste Forms," C1308, American Society for Testing and Materials, Philadelphia, PA.

20. ASTM, "Standard method of Test for Compressive Properties of Rigid Plastics, "D695, American Society for Testing and Materials, Philadelphia, PA. 